\title{
Projeção de um cenário econômico e de desmatamento para a Amazônia Legal brasileira entre 2006 e 2030
}

Economic and deforestation scenario for the Brazilian Amazon between 2006 and 2030

\author{
Terciane Sabadini Carvalho \\ Universidade Federal do Paraná \\ Edson Paulo Domingues \\ Universidade Federal de Minas Gerais
}

\section{Abstract}

The Legal Amazon was the target of development policies during the twentieth century. With different structural characteristics from the rest of Brazil and possessing the largest tropical forest of the world, the result was economic growth and deforestation. Some elements, such as the developmental policies from the 1970s and 1980s, investments in infrastructure, livestock and agriculture, have been pointed out as the determinants of deforestation. This paper presents a methodology for projecting deforestation in the different regions within the Legal Amazon caused by economic factors and structural conditions. We thus used a dynamic interregional Computable General Equilibrium (CGE) model with a specification for land use, an innovation within the literature. The results for the period under study (2006-2030) showed that regions with higher growth and deforestation would be those located in the arc of deforestation (Mato Grosso, Pará e Rondônia), especially areas of soybean and cattle production.

\section{Keywords}

Amazon; computable general equilibrium; land use; deforestation.

JEL Codes Q15; C68; Q58.

\section{Resumo}

A Amazônia Legal foi alvo de politicas desenvolvimentistas no século XX. Com características estruturais diferentes dasdo restante do Brasil e abrigando a maior floresta tropical do mundo, o resultado foi crescimento econômico e desmatamento. Alguns fatores são apontados como determinantes desse desmatamento, como as politicas de incentivo ao desenvolvimento das décadas de 1970 e 1980, os investimentos em infraestrutura, a pecuária e a agricultura. Este artigo apresenta uma metodologia de projeção para o desmatamento nas mesorregiões da Amazônia Legal, decorrente de fatores economicos e de condicionantes estruturais da região. Para isso, foi usado um modelo de Equilibrio Geral Computável (EGC) dinâmico inter-regional com uma especificação para a ocupação do solo nas regiões, isto é, uma inovação para a literatura. Os resultados para o periodo estudado(2006-2030) apontaram que as regiões com maior crescimento e desmatamento seriam aquelas situadas no arco do desmatamento(Mato Grosso, Pará e Rondônia), principalmente regiões produtoras de soja e bovinos.

\section{Palavras-chave}

Amazônia; equilíbrio geral computável; uso da terra; desmatamento.

Códigos JEL Q15; C68; Q58. 


\section{Introdução}

A Amazônia Legal foi definida para propósitos de planejamento regional em 1953 e cobre cerca de 60\% do território brasileiro. A região abriga 21 milhões de habitantes, que representa em torno de $12 \%$ da população total nacional, dos quais $70 \%$ vivem em cidades e vilarejos. Essa região engloba além dos estados do Norte do Brasil (Amazonas, Acre, Amapá, Rondônia, Roraima, Tocantins, Pará), o estado de Mato Grosso e parte do Maranhão. Alvo de muitas políticas desenvolvimentistas no século XX, a região apresenta características estruturais e econômicas diferentes das do restante do Brasil, principalmente por abrigar a maior floresta tropical do mundo. Contudo, a Amazônia não possui o mesmo bioma em toda a sua extensão. Embora a floresta tropical amazônica seja predominante, existem também outros biomas, como o cerrado e o pantanal.

Foi na década de 1960 que o governo brasileiro decidiu reduzir o "vazio demográfico" e integrar a Amazônia à economia brasileira e, para isso, construiu cerca de $60.000 \mathrm{~km}$ de estradas e assentou milhares de pessoas ao longo dessas. Um marco desse período, por exemplo, foi a construção da rodovia Belém-Brasília. Créditos, isenção de impostos e concessão de terras foram oferecidos a empresários que estivessem dispostos a investir em atividades agrícolas na região. Fundos internacionais ofereceram recursos para investimentos em hidroelétricas, portos e ferrovias, e o resultado desse processo foi o crescimento expressivo da economia, da população e do desmatamento.

Desse modo, de1960 a 1980, a Amazônia industrializou-se e apresentou os índices mais elevados de crescimento urbano do país. Contudo, os resultados desse processo em termos de desenvolvimento foram limitados. Segundo Becker (1999), a internalização da renda e do emprego foi escassa, excluindo dos benefícios gerados grande parcela da população. Ao mesmo tempo, a exploração dos recursos naturais, apoiada em incentivos fiscais, fez-se desordenadamente e com atividades inadequadas, assumindo caráter predatório na maioria das áreas ocupadas no período. Ou seja, nessa fase, o desmatamento na região apresentou taxas elevadas, principalmente em razão dos grandes empreendimentos agrícolas, da colonização rural, da abertura de estradas e dos projetos de infraestrutura e de mineração. 
Segundo o Instituto Nacional de Pesquisas Espaciais (INPE, 2013), em 2012, a área total desmatada ${ }^{1}$ na Amazônia Legal alcançou aproximada-

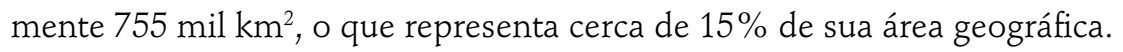
A maior parte do desmatamento, em torno de $570 \mathrm{mil} \mathrm{km}{ }^{2}$, ocorreu no período entre 1977 e 2004. No estudo sobre desmatamento na região, realizado pelo Instituto de Pesquisa Ambiental da Amazônia (IPAM), ${ }^{2}$ Alencar et al. (2004) concluíram, por meio da análise de uma extensa base de dados, que existe relação estreita entre o crescimento da economia, medido pela taxa de crescimento do Produto Interno Bruno (PIB), e o avanço da fronteira agrícola, sugerindo que a taxa de desmatamento foi influenciada ao longo do tempo pelo crescimento da economia nacional.

Alencar et al. (2004) apontaram que, a partir de 2000, se nota uma modificação dessa relação, já que a taxa de desmatamento continua aumentando mesmo com o baixo crescimento econômico do período. Tal fato sugere, de acordo com os autores, que uma nova dinâmica econômica, ligada ao mercado externo, estaria influenciando o desmatamento na região. Portanto, nos primeiros anos da década de 2000, o aumento da taxa de desmatamento seria explicado não somente pelo aumento da taxa de crescimento do PIB, mas por essa nova dinâmica, pela qual a taxa de desmatamento não está atrelada apenas ao estado da economia nacional. Nesse caso, o aumento da taxa pode refletir o crescimento do mercado internacional para os produtos amazônicos exportados, como a carne bovina e a soja.

A Figura 1 ilustra a evolução do desmatamento anual para a Amazônia Legal como um todo e para os estados que a compõem, com destaque para a queda na taxa de desmatamento a partir de 2004. Observa-se que as maiores áreas desmatadas encontram-se nos estados de Mato Grosso e do Pará, seguido por Rondônia. Entre 2009 e 2011, cerca de 70\% de todo o desmatamento observado no período ocorreu nos estados do Pará e de Mato Grosso.

1 Todavia, deve-se explicar o que se considera como terras "desmatadas". Tradicionalmente, o desmatamento na Amazônia tem sido definido como "a destruição completa e permanente da floresta" para permitir usos alternativos da terra. Isso reflete uma visão de grande parte da literatura que foca na mudança do uso da terra, reconhecendo que a tendência do desmatamento na Amazônia é guiada pela demanda por novas áreas para cultivo ou pasto, diferentemente do predomínio da demanda por madeira, que ocorre em grande parte da Ásia, ou lenha, como em parte da África (Geist; Lambin, 2002).

2 O estudo do IPAM foi resultado de uma pesquisa encomendada pelo Ministério do Meio Ambiente em julho de 2003 com o objetivo de colher informações para a elaboração do Plano de Ação para Prevenção e Controle do Desmatamento na Amazônia lançado em 2004. O estudo apresenta resultados de mais de oito anos de pesquisa científica e de experiências de campo do IPAM sobre os fatores que influenciam o desmatamento na região. 
Conforme destacado por Ferreira et al. (2005), o desmatamento na região é principalmente concentrado no chamado "arco do desmatamento", ${ }^{3}$ que compreende, além de regiões de Mato Grosso e do Pará, regiões do Maranhão, do Tocantins, de Rondônia, do Amazonas e do Acre.

\section{Figura 1 Evolução do desmatamento anual}

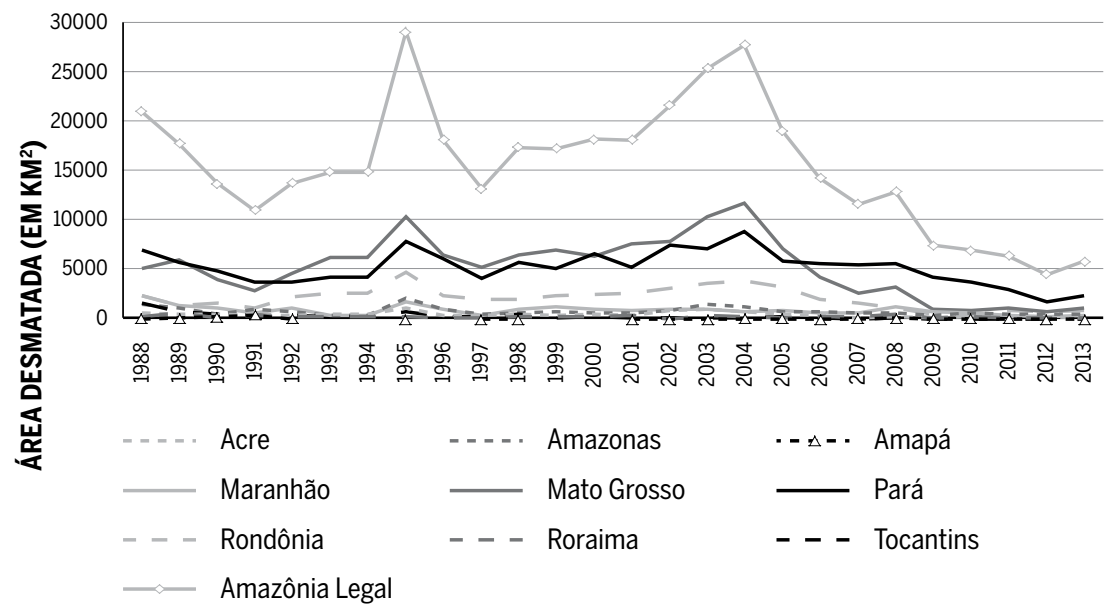

Fonte: Prodes (INPE).

Segundo alguns estudos, a queda do desmatamento de 2004 a 2012 está associada à influência de fatores econômicos, tais como a redução dos preços internacionais da soja e da carne e a valorização do real, que desestimularam as exportações. Outro fator importante seria o aumento da fiscalização, com a implementação pelo governo federal de programas de combate ao desmatamento, como o Plano de Ação para a Prevenção e Controle do Desmatamento na Amazônia (Soares Filho et al., 2009; Assunção et al., 2012). Assunção et al. (2012) afirmam que as políticas públicas de combate ao desmatamento evitaram aproximadamente $62 \mathrm{mil} \mathrm{km}^{2}$ de área desmatada entre 2005 e 2009.

$\mathrm{Na}$ literatura, ${ }^{4}$ muitos fatores são apontados como determinantes do

3 Mais especificamente, o arco do desmatamento compreende o Sudeste do Maranhão, o Norte do Mato Grosso, o Norte do Tocantins, o Sul do Pará, de Rondônia, o Sul do Amazonas e o Sudeste do Acre (Ferreira et al., 2005).

4 "O estudo da Amazônia como questão socioeconômica e demográfica surgiu no Cedeplar-UFMG, em meados dos anos 80, gerando diversos trabalhos, como a análise das possibilidades e limites de exploração da Amazônia (Sawyer, 1990). Desde então, o Cedeplar tem se 
desmatamento, como as políticas governamentais de incentivo ao desenvolvimento da região das décadas de 1970 e 1980, os investimentos em infraestrutura e a abertura de estradas, a pecuária e a conversão da floresta em vários tipos de cultivo, além de fatores geoecológicos ${ }^{5}$ e demográficos (Andersen; Reis, 1997; Pfaff et al., 2007; Chomitz; Thomas, 2003; Diniz et al., 2009). Outros fatores importantes, citados em muitos trabalhos (Araújo et al., 2009; Araújo et al., 2006; Fearnside, 2001; Alston et al., 2000) são a fragilidade das instituições, a especulação fundiária e os conflitos de terra, que favorecem a destruição dos recursos naturais e o desflorestamento.

Segundo Arima e Veríssimo (2002), as principais formas diretas de desmatamento na Amazônia são: i) a conversão de floresta em pastagens para a criação de gado, ii) o corte e a queima da floresta para cultivos na agricultura familiar e iii) a implantação de cultivos de grãos pela agroindústria. Dentre essas, a conversão de florestas para pastagens seria predominante (Margulis, 2003). Arima e Veríssimo (2002) afirmam que, com a redução drástica dos incentivos fiscais para os empreendimentos agrícolas no fim dos anos 1980, se esperava por uma redução no ritmo de desmatamento, o que não ocorreu. Nos anos 1990, outros fatores se tornaram decisivos para a manutenção do desmatamento, principalmente a exploração madeireira predatória, a pecuária extensiva e os assentamentos de reforma agrária.

Uma das principais causas do desmatamento apontada pela literatura é a pecuária extensiva e de baixa produtividade (Margulis, 2003; Mertens et al., 2002; Diniz et al., 2009). O aumento do desmatamento para o estabelecimento de pastagens de baixa produtividade é também motivado pela posse e pela especulação de terra. Esse talvez seja um dos problemas mais importantes para a política de controle do desmatamento. Segundo o Instituto Brasileiro de Geografia e Estatística (IBGE), de 1990 a2008, o rebanho da região passou de 21,1 milhões de cabeças (18\% do total nacional) para 73,9 milhões (43\% do total brasileiro) (IBGE, 2006). Aproximadamente $75 \%$ das novas reses acrescidas ao rebanho nacional provêm da Amazônia. Essa expansão, no entanto, apresenta baixíssima produtividade, repre-

notabilizado por pesquisas e trabalhos sobre a região, como os reunidos na edição 19 , volume 1, da revista Nova Economia (2009). Recentemente, o projeto URBIS Amazônia, focado nas características de urbanização da região, coordenado pelo INPE, contou com a participação de diversos pesquisadores do Cedeplar. Esse projeto contribuiu para a base de dados do modelo utilizado neste trabalho".

5 Fatores geoecológicos: qualidade do solo, precipitação, temperatura, dentre outros fatores naturais. 
sentando menos de uma cabeça por hectare (MMA, 2012; Alencar et al., 2004), o que sugere seu uso também para fins especulativos.

O crescimento da produção de grãos na Amazônia, principalmente da soja, também tem sido apontado como um dos motivos para o aumento das taxas de desmatamento a partir do fim da década de 1990. No caso da soja, a influência sobre o desmatamento é predominantemente indireta. Sua expansão tem acontecido fundamentalmente em pastagens já formadas, onde o custo de implantação da atividade é menor. No entanto, ao ocupar as pastagens existentes, a soja acaba pressionando a expansão da pecuária para outras áreas de florestas (Alencar et al., 2004). Desde 1990, a população de gado na Amazônia aumentou de 25 milhões para mais de 70 milhões, e a área de soja, de $16.000 \mathrm{~km}^{2}$ para mais de $60.000 \mathrm{~km}^{2}$ (IBGE, 2010). O crescimento da produção agrícola veio com a perda de 700.000 $\mathrm{km}^{2}$ de florestas. Arima et al. (2011) consideram que essa mudança indireta no uso da terra na Amazônia, conhecida como ILUC (indirect land use change), não é somente mensurável, mas que seu impacto é significativo.

Diversos trabalhos consideram que, nas duas últimas décadas do século XXI, o processo de desmatamento estaria ligado principalmente ao mercado externo, impulsionado pela rentabilidade das principais atividades exportadoras, como a extração madeireira, a pecuária e a agroindústria (Margulis, 2003; Alencar et al., 2004). Nesse período, observou-se a remoção de políticas de incentivos fiscais e subsídios que estimularam o desmatamento e o aumento da influência dos mercados globais sobre a economia da Amazônia (Nepstad et al., 2009; Cattaneo, 2008). Alguns trabalhos verificaram que existe correlação positiva entre o crescimento dos mercados globais por commodities e a conversão de floresta tropical para uso agrícola, que passaram a substituir a demanda local como principal vetor de desmatamento (DeFries; Rosenzweig, 2010; Rudel et al., 2009).

Segundo as projeções de Gouvello (2010) e Soares Filho et al. (2005), o desmatamento amazônico, apesar da redução em suas taxas entre 2004 e 2011, poderá se expandir nas próximas décadas. Estima-se que até 2040 o desmatamento projetado pode eliminar $40 \%$ dos atuais 5,4 milhões de $\mathrm{km}^{2}$ de florestas, caso o padrão de ocupação siga a trajetória das últimas duas décadas (Soares Filho et al., 2005). As últimas estimativas do desmatamento na Amazônia, divulgadas pelo INPE (INPE, 2013), mostraram que, no período 2012-2013, houve aumento da taxa de desmatamento de cerca de $30 \%$ (vide Figura 1), o que parece corroborar essas projeções. Embora 
seja a segunda menor taxa registrada desde o início do monitoramento, em 1988, é um indício de que o desmatamento pode aumentar no futuro.

A perspectiva do aumento do desmatamento na Amazônia ganha ainda mais força ao se considerar a aprovação de algumas medidas do Novo Código Florestal, ${ }^{6}$ em maio de 2012, que, dentre outros aspectos, trata das Áreas de Preservação Permanente (APPs) e das Reservas Legais (RL). Dentre alguns dos pontos do Novo Código, estão a redução do limite da RL na Amazônia Legal ${ }^{7}$ e a regularização de cultivos de pequenos proprietários, excluindo-os da obrigatoriedade de recuperarem áreas que foram desmatadas em APPs. Um estudo recente do Instituto de Pesquisa Econômica Aplicada (IPEA) analisou a proposta do novo código (IPEA, 2011). O estudo concluiu que, com a manutenção dos principais pontos da proposta, cerca de 29 milhões de hectares de mata nativa deixariam de ser recuperados no país, em uma perspectiva mais otimista, com o agravante de intensificação significativa do desmatamento, na mais pessimista.

Neste contexto, um exercício de projeção do desmatamento na Amazônia Legal decorrente de um cenário de crescimento macroeconômico nacional hipotético, assim como das mudanças indiretas do uso da terra, torna-se relevante. O cenário de crescimento vai permitir a projeção do desmatamento motivado por fatores econômicos, ${ }^{8}$ como o aumento da demanda externa e da produção nas diferentes mesorregiões. Para isso, este artigo utiliza uma metodologia que simula o crescimento econômico de 30 mesorregiões da Amazônia entre 2006 e 2030 e o desmatamento resultante desse crescimento. Trata-se de um modelo dinâmico de equilíbrio geral computável (EGC) inter-regional para as 30 mesorregiões da Amazônia Legal, denominado RE-

6 O Código Florestal Brasileiro foi criado pela Lei n 4.771, de 15 de setembro de 1965. O Código estabelece limites de uso da propriedade, que deve respeitar a vegetação existente na terra, considerada bem de interesse comum a todos os habitantes do Brasil. O primeiro Código Florestal Brasileiro foi instituído pelo Decreto n²3.793, de 23 de janeiro de 1934.

7 A parcela a ser preservada no Código Florestal atual é de $80 \%$ e caiu para $50 \%$ em estados que tenham $65 \%$ de áreas protegidas ou terras indígenas em seu território.

8 Alguns estudos que projetam desmatamento utilizam uma modelagem de sistemas ambientais baseada em técnicas SIG (Sistema de Informação Geográfica). Bittencourt (2011), por exemplo, projetou o desmatamento na Amazônia até 2020 utilizando esse método com diversas variáveis explicativas, tais como: distância de áreas protegidas, distância de todas as estradas, distância de centros urbanos, distância de centros de extração madeireira, rios navegáveis, gasodutos, assentamentos rurais, os tipos de solos e vegetação, a declividade do terreno e a altitude. Contudo, seu modelo não incluiu variáveis explicativas socioeconômicas, embora esses indicadores afetem as taxas de desmatamento e as mudanças no uso do solo. Isso em razão da dificuldade de encontrar dados socioeconômicos na resolução adequada aos modelos dinâmicos de paisagem. 
GIA (Inter-Regional General Equilibrium Model for the Brazilian Amazon). ${ }^{9}$ O REGIA possui um módulo de mudança indireta de uso da terra (ILUC - indirect land use change model), que permite modelar a conversão entre quatro categorias diferentes de uso da terra (floresta natural, floresta plantada, lavoura e pasto). Incorporar explicitamente o uso da terra em um modelo EGC permite simular como diversas conjunturas externas afetam a disponibilidade de terras aptas à agropecuária e permite que fatores econômicos contribuam para a extensão das respostas dos agricultores a tais cenários.

Assim, além desta introdução, este artigo se divide em mais quatro seções. A primeira descreve a metodologia, apresentando o modelo REGIA e sua estrutura teórica, o módulo ILUC e a construção da base de dados. A segunda seção apresenta o fechamento e os mecanismos da simulação realizada. Na terceira, têm-se os resultados do cenário de crescimento econômico e desmatamento. E, por fim, tecem-se as considerações finais e conclusões.

\section{Metodologia}

\subsection{0 modelo REGIA}

O REGIA é um modelo de Equilíbrio Geral Computável (EGC) com dinâmica recursiva e modelagem do uso da terra para 30 mesorregiões que fazem parte da Amazônia Legal brasileira ${ }^{10}$ e o restante do Brasil. Trata-se de um modelo bottom-up, isto é, um modelo multirregional, em que os resultados nacionais são agregações dos resultados regionais. Além disso, é o primeiro modelo EGC construído para a economia da Amazônia que apresenta essa desagregação regional.

Possui alguns avanços em relação a outros modelos que analisaram questões relacionadas à Amazônia e ao desmatamento, tais como Pattanayak et al. (2009) e Cattaneo (2001). O primeiro é o tratamento do uso da terra em um modelo com dinâmica recursiva, permitindo analisar os impactos dos diferentes cenários ao longo do tempo e o ajuste endógeno

9 REGIA remete à planta aquática vitória-régia, típica da região da Amazônia. Ela possui uma grande folha em forma de círculo, que fica sobre a superfície da água, e pode chegar a ter até 2,5 metros de diâmetro e suportar até 40 quilos, se bem distribuídos em sua superfície. 10 Ao longo do texto, utiliza-se o termo "Amazônia" como referência à Amazônia Legal brasileira. 
da oferta de terra. E o segundo é a maior desagregação, 30 mesorregiões da Amazônia e o restante do Brasil. Essa desagregação foi definida a fim de obter as especificidades e as características diferenciadas das regiões que compõem a Amazônia, sem comprometer a operacionalização do modelo.

O REGIA apresenta estrutura teórica semelhante ao modelo IMAGEM$-\mathrm{B}^{11}$ construído no Cedeplar-UFMG. Assim como o IMAGEM-B, o modelo parte da estrutura teórica do TERM, acrônimo em inglês para The Enormous Regional Model (Horridge et al., 2005), modelo multirregional bottom-up EGC do tipo Johansen que decorre do contínuo desenvolvimento do modelo ORANI (Dixon et al., 1982) e de sua versão genérica, o ORANI-G (Horridge, 2000). O TERM foi desenvolvido para lidar com dados regionais desagregados, mas que também permitisse uma geração de soluções para as simulações mais rápidas do que nos modelos disponíveis (Horridge et al., 2005).

Muitos modelos foram desenvolvidos usando a estrutura teórica do TERM australiano, tais como o TERM-BR para o Brasil, desenvolvido nos trabalhos de Ferreira Filho e Horridge (2006; 2008; 2010; 2011; 2012; 2014) e Ferreira Filho et al. (2007). O TERM-BR também foi utilizado nos trabalhos de Santos (2006), Fachinello (2008), Pavão (2008), Diniz (2012), dentre outros. O modelo SinoTERM foi construído para a China (Horridge; Wittwer, 2008; Horridge; Wittwer, 2009), e o modelo TERM, para a Indonésia (Pambudi; Smyth, 2008). O desenvolvimento do TERM australiano também deu origem ao TERM-H2O, utilizado para analisar problemas relacionados a políticas de gerenciamento de água na Austrália (Wittwer, 2012).

O REGIA é composto de blocos de equações que determinam relações de demanda e oferta, de acordo com hipóteses de otimização e condições de equilíbrio de mercado. Além disso, vários agregados nacionais são definidos nesses blocos, como nível de emprego agregado, PIB, saldo comercial e índices de preços. Os setores produtivos minimizam os custos de produção sujeitos a uma tecnologia de retornos constantes de escala, em que as combinações de insumos intermediários e fator primário (agregado) são determinados por coeficientes fixos (Leontief). Há substituição via preços entre produtos domésticos e importados na composição dos insumos via função de elasticidade de substituição constante (CES). Uma especificação CES também controla a alocação do composto doméstico entre as diver-

11 O modelo IMAGEM-B foi construído com base no modelo TERM (Horridge et al., 2005) para a análise dos impactos regionais do Plano Plurianual 2008-11 (PPA) de investimentos do governo federal (Ministério do Planejamento, Orçamento e Gestão, 2008). 
sas regiões. Também ocorre substituição entre capital, trabalho e terra na composição dos fatores primários por meio de funções CES; entretanto, o fator terra está alocado apenas nos setores de agricultura e pecuária.

Os produtos de determinada região direcionados a outra são compostos dos valores básicos e das margens de comércio e transporte. A participação de cada margem no preço de entrega é uma combinação de origem, destino, produto e fonte (doméstico ou importado). As margens sobre os produtos de uma região para outra podem ser produzidas em diferentes regiões. Espera-se que as margens sejam distribuídas mais ou menos equitativamente entre origem e destino, ou entre regiões intermediárias no caso de transporte entre regiões mais distantes. Existe substituição nos fornecedores de margem de acordo com uma função CES.

No modelo, há uma família representativa para cada microrregião, que consome bens domésticos (das microrregiões) e bens importados. A escolha entre domésticos e importados (de outros países) é realizada por uma especificação CES (hipótese de Armington). ${ }^{12} \mathrm{O}$ tratamento da demanda das famílias é baseado num sistema combinado de preferências CES/Klein-Rubin. Assim, a utilidade derivada do consumo é maximizada segundo tal função de utilidade. Essa especificação dá origem ao sistema linear de gastos (LES), ${ }^{13}$ no qual a participação do gasto acima do nível de subsistência, para cada bem, representa uma proporção constante do gasto total de subsistência de cada família.

O modelo REGIA possui uma especificação de dinâmica recursiva, em que o investimento e o estoque de capital seguem mecanismos de acumulação e de deslocamento intersetorial valendo-se de regras preestabelecidas, associadas a taxas de depreciação e de retorno. Desse modo, uma das modificações para tornar o REGIA dinâmico é ligar os fluxos de investimentos anuais aos estoques de capital. $\bigcirc$ modelo não inclui um processo de ajuste temporal do mercado de trabalho. Para a simulação deste artigo, que apresenta um horizonte temporal de 25 anos, adotou-se uma configuração em que o emprego nacional é exógeno (entre 2006 e 2011, ajustado com dados observados e a partir de 2012, determinado pelo crescimento

12 Hipótese de Armington - bens de origens diferentes são tratados como substitutos imperfeitos. 13 O LES é adequado para amplos agregados de bens em que substituições específicas não são consideradas. Isto é, elasticidades de preços-cruzados são iguais ao efeito renda dado na equação de Slutsky sem qualquer contribuição dos efeitos de preço-cruzado. Isso implica que todos os bens são complementares fracos. O sistema linear de gastos não permite a inclusão de bens inferiores (i.e., elasticidades renda negativas). 
populacional). Isso implica uma resposta endógena do salário médio, com diferenciais de salário setoriais e regionais fixos. Assim, há mobilidade intersetorial e regional de trabalho.

O consumo do governo é exógeno. O modelo opera com equilíbrio de mercado para todos os bens, tanto domésticos quanto importados, assim como no mercado de fatores (capital, terra e trabalho) em cada microrregião. Os preços de compra para cada um dos grupos de uso em cada microrregião (produtores, investidores, famílias, exportadores e governo) são a soma dos valores básicos e dos impostos sobre vendas (diretos e indiretos) e margens (de comércio e transporte). Impostos sobre vendas são tratados como taxas ad-valorem sobre os fluxos básicos. As demandas por margens (transporte e comércio) são proporcionais aos fluxos de bens aos quais as margens estão conectadas.

\subsection{0 modelo ILUC}

Um dos diferenciais do REGIA é a incorporação de um modelo de uso da terra conhecido na literatura como ILUC (indirectland use change). A terra é um dos fatores primários do modelo, assim como o capital e o trabalho, e é utilizada na produção dos setores agrícolas. $O$ uso da terra é modelado separadamente para cada uma das regiões, mantendo fixa a área total. $\bigcirc$ uso da terra é dividido em quatro tipos: i) lavoura, ii) pasto, iii) floresta plantada e iv) floresta natural e demais áreas. A área de lavoura é utilizada na produção de onze setores, a área de pasto em cinco setores, e a floresta plantada é usada no setor de silvicultura e exploração florestal (ver Quadro 1). No modelo, os setores/produtos agrícolas, assim como o uso da terra, são específicos para cada região.

Assume-se que cada setor do modelo esteja ligado a um tipo de uso da terra. A área de floresta natural e demais usos é definida como a área total de cada mesorregião menos as áreas de lavoura, pasto e floresta plantada. Isto é, inclui todas as áreas não utilizadas nos sistemas agroflorestais, como florestas naturais, áreas urbanas, montanhas, estradas e rios. Considera-se que estas últimas áreas mudem mais lentamente do que as florestas naturais, e, portanto, a mudança (queda) desse tipo de uso da terra é uma proxy para medir o desmatamento em relação à expansão da agropecuária ou da silvicultura. 
Quadro 1 Descrição dos setores no uso do fator terra

\begin{tabular}{l|l}
\hline Uso da terra & \multicolumn{1}{c}{ Produtos } \\
\hline \multirow{3}{*}{ Lavoura } & 1.Arroz em casca, 2. Milho em grão, 3. Trigo e cereais, 4. Cana-de-açúcar, \\
& $\begin{array}{l}\text { 5. Soja em grão, 6. Outros da lavoura, 7. Mandioca, 8. Fumo em folha, } \\
\text { 9. Algodão herbáceo, 10.Frutas cítricas e 11. Café em grão }\end{array}$ \\
\hline Pasto & 1. Bovinos, 2. Leite e vaca, 3. Suínos, 4. Aves vivas, 5. Ovos \\
\hline Floresta plantada & 1. Exploração florestal e silvicultura \\
\hline
\end{tabular}

Fonte: Elaboração própria.

fator terra pode ser alocado entre os diferentes setores agrícolas de acordo com os diferenciais de remuneração. Assim, a demanda por terra no modelo responde às variações da remuneração do fator em cada setor. Desse modo, cada uso de terra (lavoura, floresta plantada e pasto) é distribuído no ano t segundo uma função CET entre os diferentes produtos para cada região. Na forma percentual, tem-se:

$$
x_{i r}=x_{r}+\alpha_{\text {lnd }}\left(p_{i r}-p_{r}\right)
$$

em que $x_{i r}$ é a mudança percentual da demanda por terra alocada para o produto $i^{14}$ na região $r$. $p_{i r}$ é a mudança percentual na remuneração da terra para o produto $i$ na região $r$. Já $x_{r}$ é a variação percentual do insumo total terra (lavoura, pasto e floresta plantada) na região $r$, e $p_{r}$ é a remuneração média de todos os produtos na região $r$. Assim, se em determinada região a remuneração do setor $i$ é superior à remuneração média da região $\left(p_{i r}-p_{r}>0\right)$, ocorrerá mudança positiva de terra em direção ao cultivo $i$.

A variação total na demanda por cada uso de terra para cada região é dada por $x_{r}=\sum_{k} S_{k} x_{k}$ usando a distribuição de remuneração, $S_{k}$, com $k$ representando os diversos usos da terra (lavoura, pasto e floresta plantada). Deve-se adotar, porém, um limite físico da área total da região $r$, que será $\sum_{k} H_{k} x_{k}=0$, usando a distribuição de hectares, $H_{k}$. Desse modo, para

$14 i=1$ (arroz em casa), 2 (milho em grão), 3 (trigo e cereais), 4 (cana-de-açúcar), 5 (soja em grão), 6 (outros produtos da lavoura), 7 (mandioca), 8 (fumo em folha), 9 (algodão herbáceo), 10 (frutas cítricas), 11 (café em grão), 12 (exploração florestal e silvicultura), 13 (bovinos), 14 (leite e vaca), 15 (suínos), 16 (aves) e 17 (ovos). Os produtos de 1 a 11 estão ligados no código do modelo ao tipo de terra lavoura, o produto 12 está atrelado ao uso de floresta plantada, e, por fim, os produtos 13 a 17, ao uso pasto. 
manter a área total constante, utiliza-se uma variável física em hectares, $n_{k r}$, para cada uso da terra por região $r$, computada por:

$$
n_{k r}=x_{k r}+\mu
$$

em que $\mu$ é calculado tal que $0=\sum_{k} H_{k} n_{k}$, garantindo que a oferta física total de terra seja fixa. Dessa maneira, a demanda por terra, segundo os diferentes usos, é ligada à oferta de terra no modelo. A ideia é que a demanda por terra, $x_{k r}$, influencia o processo de conversão de terra entre os usos, ou seja, o lado da oferta, $n_{k r}$. No REGIA, isto é operacionalizado ao determinar que a variação da demanda por terra é igual avariação da oferta de terra. Esse mecanismo garante o equilíbrio no mercado de terra, fixando a oferta total de terra regional disponível.

lado da oferta de terra vai permitir que o fator se mova entre as diferentes categorias de terra entre o ano $t$ e o ano $t+1$. Uma função CET não conseguiria capturar o processo de conversão entre os tipos de usos da terra. Para isso, o processo de conversão é controlado por meio de uma matriz de transição que representa as possibilidades de conversão da terra entre o ano $t$ e o ano $t+1$. A matriz representa a mobilidade da terra entre os usos, indicando as possibilidades de transformação dos diferentes usos da terra.

A matriz de transição captura o fato de que terras mais produtivas são inicialmente utilizadas no processo produtivo, e, ao mesmo tempo, a utilização marginal da terra que poderia ser convertida em uso produtivo é limitada. $\bigcirc$ processo econômico de conversão da terra ocorre da seguinte forma: as florestas seriam inicialmente convertidas em áreas para pasto, que, após algum tempo, estariam aptas para ser convertidas em áreas para lavoura (Ferreira Filho; Horridge, 2012; Cattaneo, 2002; Macedo et al., 2012; Barona et al., 2010). Portanto, a matriz mostra que a conversão entre os usos, por exemplo, entre pasto e lavoura é mais fácil de ser realizada do que entre floresta natural para a lavoura diretamente. Se a diferença entre a quantidade de terra empregada na produção agrícola e a área total da região é grande, então os aumentos na demanda por terra vão conduzir a maior conversão de terra para a utilização agrícola. Isso, por sua vez, vai levar a um aumento na remuneração da terra para compensar os custos associados a essa conversão.

No REGIA, a matriz de transição foi construída baseada na metodologia de Ferreira Filho e Horridge (2014), calibrada com os dados de satélite do 
TerraClass ${ }^{15}$ de 2008 e 2010 (obtidos do PRODES/INPE), e do Censo Agropecuário de 1995 e $2006^{16}$ (IBGE) para as 30 mesorregiões da Amazônia Legal. A matriz calibrada indica como o uso da terra muda entre os diferentes tipos (lavoura, pasto, floresta plantada e florestal natural) ao longo do tempo. Entre dois períodos (anos), o modelo permite que a terra se mova entre lavoura, pasto, floresta plantada, ou que floresta natural se converta em um dos três. As possibilidades de conversão ${ }^{17}$ utilizadas na matriz de transição são ilustradas no Quadro 1. A soma das linhas representa o uso da terra no ano $t$, e a soma das colunas representa o uso da terra no ano $t+1$, valores retirados do banco de dados do TerraClass e do Censo Agropecuário. A matriz é construída usando um método de ajuste biproporcional, conhecido como $\mathrm{RAS},{ }^{18}$ de escalonamento de linhas e colunas. Os elementos que estão fora da diagonal mostram as áreas de terra que mudaram entre os dois períodos.

A Tabela 1 ilustra que, em uma região, $90 \%$ do total de terra em $t$ permanece sendo o mesmo uso em $t+1$ (soma da diagonal principal). A primeira coluna mostra que $2,25 \%$ do que seria pasto em $t$ se transformaria em lavoura em $t+1$, e $0,23 \%$ do que seria floresta plantada, e $0,23 \%$ de floresta natural se converteria em lavoura em $t+1$. Nota-se que $2,25 \%$ do que seria floresta natural transformar-se-ia em pasto em $t+1$, e 2,25\% se transformaria em floresta plantada.

15 Este artigo se insere no âmbito do projeto URBISAmazônia, que discute os fatores sociais e econômicos que influenciam o processo de urbanização na Amazônia. Esse projeto é realizado por meio de uma equipe multidisciplinar liderada pelo INPE, que disponibilizou os dados do TerraClass para a construção da matriz de transição para o modelo REGIA. Link com as produções do projeto URBISAmazônia: <http://www.dpi.inpe.br/urbisAmazonia/ doku.php?id=urbis:producao $>$

16 Os dados usados para a construção da matriz de transição foram retirados do TerraClas; porém, como a fonte de dados para a produção setorial foi o IBGE, alguns ajustes tiveram que ser feitos usando os dados do Censo Agropecuário, uma vez que alguns setores apresentavam produção, segundo os dados do IBGE, mas não apresentavam área cultivada, de acordo com os dados do TerraClass. Todavia, esse ajuste foi mínimo, em menos de $10 \%$ dos dados de uso da terra. A opção pelos dados do TerraClass se explica pela qualidade das informações de dados de satélite comparativamente aos dados do Censo Agropecuário, que se baseia nas respostas dos agricultores.

17 As possibilidades de transição, do Quadro 2, utilizadas para calcular a matriz de transição, são valores hipotéticos e foram baseados na direção de conversão do uso de terra, que supõe que as florestas naturais seriam inicialmente convertidas em áreas para pasto e que, após algum tempo, estariam aptas para serem convertidas em áreas para lavoura.

18 O método RAS é um mecanismo interativo, que busca ajustar os valores das linhas e colunas de uma matriz, com seus totais, considerando a proporcionalidade dos valores totais. Esse método calcula um novo conjunto de valores para as células de uma matriz baseando-se em uma estrutura já existente, fazendo com que a soma das linhas e dascolunas fiquem consistentes com o total esperado. Mais informações sobre o método RAS podem ser encontradas em Miller e Blair (2009). 
Tabela 1 Hipótese de transição de uso da terra utilizado no modelo REGIA

\begin{tabular}{lrr|r|r|r}
\hline $\begin{array}{l}\text { Possibilidades } \\
\text { de Conversão }\end{array}$ & Cultura & Pasto & $\begin{array}{r}\text { Floresta } \\
\text { Plantada }\end{array}$ & $\begin{array}{r}\text { Floresta } \\
\text { Natural e } \\
\text { outros }\end{array}$ & $\begin{array}{r}\text { Total } \\
\text { ano t }\end{array}$ \\
\hline Cultura & 22,50 & 0,23 & 0,02 & 0,02 & 22,77 \\
\hline Pasto & 2,25 & 22,50 & 0,23 & 0,02 & 25,00 \\
\hline Floresta Plantada & 0,23 & 2,25 & 22,50 & 0,02 & 25,00 \\
\hline Floresta Natural e outros & 0,23 & 2,25 & 2,25 & 22,50 & 27,33 \\
\hline Total ano t+1 & 25,20 & 27,23 & 25,00 & 22,57 & 100,00 \\
\hline
\end{tabular}

Fonte: Elaboração própria.

A oferta de terra em cada categoria (lavoura, pasto, floresta plantada e floresta natural) para cada região aumenta de acordo com a taxa anual de crescimento percentual de cada uso dado pela matriz de transição:

$$
N_{k, t+1}=100 * \Delta N_{k,(t+1, t)} / N_{k, t}
$$

Além dessa taxa de crescimento anual, para ajustar a matriz de transição para o próximo período, o estoque corrente de terra em $t$ é distribuído para o próximo ano $t+1$, respondendo às variações da remuneração da terra. As matrizes de transição podem ser expressas na forma de participação percentual (isto é, o total da soma das linhas igual a 1), mostrando as probabilidades que um hectare particular de terra usado para o pasto seja usado no próximo ano para a lavoura. No REGIA, essas probabilidades ou proporções são modeladas como uma função da variação da rentabilidade de cada tipo de terra:

$$
S_{p k r}=\mu_{p r} \cdot L_{p k r} \cdot P_{k r}^{\beta_{h d}} \cdot M_{k r}
$$

em que o subscrito $r$ denota região. $S_{p k r}$ é a participação da terra do tipo $p$, que se transforma em $k$ na região $r$. Por sua vez, $\mu_{p r}$ é uma variável de ajuste para assegurar que $\sum_{k} S_{p k r}=1$. $L_{p k r}$ é uma constante de calibração que representa o valor inicial de $S_{p k r}$ (dado pela matriz de transição). $P_{k r}^{\beta_{h d}}$ é a remuneração unitária média do tipo de terra $k$. $\beta_{l \text { lnd }}$ é um parâmetro de sensibilidade que mede a resposta da oferta de terra em relação às variações da remuneração. $M_{k r}$ é uma variável de deslocamento de valor inicial igual a 1 .

O parâmetro de sensibilidade, $\beta_{\text {lnd }}$, representa a elasticidade da oferta de terra e foi calculado de acordo com a metodologia utilizada em Van Meijl 
et al. (2006) e Farias (2012). A elasticidade da oferta de terra com relação aos retornos da terra deve refletir que, quanto maior a disponibilidade de terra, maior deve ser o valor dessa elasticidade. A maior disponibilidade de terra implica maior facilidade no processo de conversão de terra em termos de custos. Assim, se a remuneração de lavoura aumenta em relação à remuneração do pasto no ano $t$ (lado da demanda), a taxa de conversão de pasto para a lavoura vai aumentar, e, assim, a quantidade de terra destinada à lavoura em $t+1$ também aumenta. Para modelar a taxa de conversão de florestas naturais, foi necessário considerar uma remuneração fictícia, no caso, o Índice de Preços ao Usuário Final. Desse modo, a matriz de transição é ajustada anualmente, assim como a oferta de terra.

\subsection{Base de dados}

A base de dados do modelo REGIA foi construída por meio de um processo de regionalização da matriz de insumo-produto nacional de 2005 . $\bigcirc$ procedimento partiu da metodologia proposta em Horridge (2006), adaptada para o caso brasileiro. Com base nos dados da matriz de insumo-produto de 2005 diagonalizada (110 setores e 110 produtos) e de um grande conjunto de indicadores regionais, estimou-se uma matriz de comércio inter-regional por meio de fórmulas utilizando uma matriz de distâncias e uma abordagem gravitacional. A principal hipótese da abordagem gravitaciona $1^{19}$ é que o comércio inter-regional está baseado na distância entre as regiões e na interação derivada do tamanho de suas economias.

Detalhes do procedimento de construção da base de dados do modelo estão em Carvalho (2014). O resultado desse procedimento é a total consistência da base de dados com os dados oficiais das Contas Regionais, das Contas Nacionais, da Matriz de Insumo-Produto, das informações do IBGE; e Comércio Exterior (SECEX), Produção Industrial (PIA) e Emprego (RAIS). ${ }^{20} \mathrm{Um}$ dos componentes mais importantes da base de dados para

19 Uma difundida justificativa teórica à ideia de que os fluxos bilaterais de comércio dependem positivamente da renda das regiões e negativamente da distância entre elas baseia-se em um modelo de comércio desenvolvido por Krugman (1980). Mais detalhes do método e algumas aplicações podem ser vistos em Miller e Blair (2009).

20 Optou-se pelo método de regionalização do modelo EGC porque não existem matrizes de insumo-produto por mesorregião para a Amazônia Legal. Uma matriz de insumo-produto para o estado do Pará é utilizada em Costa (2008), mas seu procedimento de construção não 
as simulações deste trabalho é a remuneração e o uso do fator terra por mesorregião na Amazônia. No modelo, o fator terra foi alocado para os setores agricultura e pecuária. A remuneração do fator terra foi obtida pelos dados das "Despesas realizadas pelos estabelecimentos - Arrendamento de terras" do Censo Agropecuário de 2006 (IBGE). ${ }^{21}$

\section{Fechamento e simulação}

\subsection{Fechamento do modelo}

O fechamento do modelo é a determinação dos conjuntos de variáveis endógenas e exógenas das simulações realizadas, representando as hipóteses sobre o funcionamento da economia e seus ajustamentos. O REGIA é um modelo dinâmico e permite a acumulação do capital ao longo do tempo e ajustes no mercado de terra. Para a simulação de dinâmica recursiva do presente artigo, foram utilizados dois fechamentos distintos para o cenário de crescimento.

No modelo, assume-se que o consumo regional segue a renda regional, com propensão marginal a consumir exógena. Além, disso, supõe-se que o gasto do governo segue a renda das famílias nacional e regionalmente. Outra pressuposição é que o fator terra para "florestas naturais e demais usos" é exógeno para as regiões do modelo que não possuem floresta tropical e onde a capacidade de expansão da agropecuária via desmatamento seja pequena. No REGIA, esse grupo de mesorregiões é formado por: Sudeste Mato-Grossense, Centro-Sul Mato-Grossense, Sul Maranhense, Leste Maranhense, Oriental de Tocantins e Restante do Brasil. O modelo trabalha com preços relativos, e a variável escolhida como numerário foi o Índice de Preços ao Consumidor.

está descrito.

21 A divisão dessa informação entre pecuária e agricultura foi feita de acordo com os valores de arrendamento de terras por grupo de atividade. Por exemplo, para a agricultura, foram somados os valores de arrendamento dos grupos: produção de lavoura temporária, horticultura e floricultura, produção de lavouras permanentes, sementes, mudas e outras formas de propagação vegetal e produção florestal. Já para a pecuária, foram somados os valores de arrendamento da pecuária e criação de outros animais, pesca e aquicultura. Como a base de dados do modelo é 2005, foi aplicado um deflator para que os valores monetários do Censo se equiparassem aos da matriz de insumo-produto. Assim, obteve-se a remuneração da terra em termos nacionais para agricultura e pecuária. $O$ último passo foi dividir a remuneração da terra por microrregião e para isso considerou-se que o valor dessa é proporcional à produção da agricultura e da pecuária em cada região. 
O primeiro fechamento corresponde ao período de 2006 a 2011, em que são considerados exógenos os principais agregados macroeconômicos: PIB real, investimento, consumo das famílias, gastos do governo, volume de exportações e emprego agregado, além das taxas de desmatamento por mesorregião. Desse modo, as variáveis de deslocamento para a taxa de retorno bruta, o salário nacional, a demanda do governo, a quantidade exportada e o uso da terra, assim como a variável de mudança tecnológica dos fatores de produção são endógenas.

Para o segundo fechamento, referente ao período de projeção de 2012 a 2030, as variáveis macroeconômicas agregadas para o PIB, consumo das famílias e gastos do governo são mantidas exógenas, e os demais agregados macroeconômicos e as taxas de desmatamento regionais passam a ser endógenas. Em ambos os fechamentos, tem-se o crescimento populacional e o índice de preços dos importados como variáveis exógenas.

\subsection{Simulação}

O cenário de crescimento apresenta a trajetória da economia para o período de 2006 a 2030. De 2006 a 2011, foram utilizados indicadores macroeconômicos nacionais observados, assim como taxas de desmatamento regionais observadas. Os dados para as variáveis econômicas foram retirados das contas nacionais (IBGE): PIB real, consumo das famílias, gastos do governo, investimento e exportações. Outros dados incorporados foram o preço médio dos importados (calculado com base nos dados da FUNCEX), o emprego agregado e o crescimento populacional (IBGE). A Tabela 2 apresenta os dados para esses indicadores.

As taxas de desmatamento por mesorregião também são consideradas exógenas para o período de 2006 a 2011, com base nos dados do INPE. Os dados foram retirados do programa PRODES, ${ }^{22}$ que apresenta a área desmatada por município da Amazônia Legal. Conforme foi explicado na seção sobre o módulo de uso da terra, o REGIA apresenta uma categoria

22 Projeto PRODES: Monitoramento da Floresta Amazônia Brasileira por Satélite. Desde 1988, o INPE é o responsável por produzir as "Taxas Anuais do Desflorestamento da Amazônia Legal". A partir do ano de 2002, essas estimativas começaram a ser produzidas por classificação digital de imagens, seguindo a "Metodologia Prodes". A principal vantagem desse procedimento está na precisão do georreferenciamento dos polígonos de desflorestamento, de forma a produzir um banco de dados geográfico multitemporal. 
para a área de florestas naturais e demais usos, que é a área total de cada mesorregião menos as áreas de lavoura, pasto e silvicultura. Isso significa que essa inclui, além das florestas naturais, áreas urbanas, rios, dentre outras. Desse modo, a taxa de desmatamento foi calculada como a área desmatada por mesorregião do INPE (agregando os dados municipais) em relação à área de floresta natural e demais usos.

Tabela 2 Variáveis do cenário macroeconômico para o período de 2006 a 2011 em variação \% a.a.

\begin{tabular}{lrrrr|r|r|r}
\hline Indicadores & $\mathbf{2 0 0 6}$ & $\mathbf{2 0 0 7}$ & $\mathbf{2 0 0 8}$ & $\mathbf{2 0 0 9}$ & $\mathbf{2 0 1 0}$ & $\mathbf{2 0 1 1}$ \\
\hline PIB agregado & 3,95 & 6,10 & 5,23 & $-0,33$ & 7,58 & 2,75 \\
\hline Investimento & 9,80 & 13,75 & 13,65 & $-6,65$ & 22,13 & 4,88 \\
\hline Consumo das Famílias & 5,20 & 6,10 & 5,70 & 4,40 & 6,90 & 4,10 \\
\hline Gastos do Governo & 2,60 & 5,10 & 3,20 & 3,10 & 4,20 & 1,90 \\
\hline Volume de Exportações & 5,00 & 6,20 & 0,50 & $-9,10$ & 11,50 & 4,50 \\
\hline Emprego Agregado & $-0,15$ & 0,73 & 1,58 & $-0,19$ & 1,46 & 0,82 \\
\hline Crescimento Populacional & 1,19 & 1,12 & 1,05 & 0,99 & 0,93 & 0,87 \\
\hline Preços dos Importados & 6,97 & 8,24 & 21,81 & $-11,12$ & 3,90 & 14,28 \\
\hline
\end{tabular}

Fonte: Elaboração própria com base em dados das Contas Nacionais, FUNCEX e IBGE.

Para o período de projeção econômica, entre 2012 e 2030, é considerado um cenário hipotético de crescimento da economia nacional de $3 \%$ ao ano. ${ }^{23}$ Desse modo, é projetado um crescimento das variáveis agregadas para PIB real, consumo das famílias e gastos do governo a $3 \%$ ao ano (seguindo o crescimento do PIB), enquanto o crescimento populacional é fixado em $1 \%$ ao ano (de acordo com projeções do IBGE).

Além dessas variáveis, são utilizadas projeções de exportações de soja e bovinos, retirados de Nassar (2011). A justificativa para utilizar uma projeção de crescimento das exportações de soja e de bovinos se baseia no fato de que o mercado externo para esses produtos vem sendo considerado como importante vetor do desmatamento na região. Além disso, esses produtos são importantes na dinâmica econômica da Amazônia. As estimativas de Nassar (2011) são consistentes com as projeções da FAO (2003).

23 Este número está próximo da taxa média histórica dos últimos 30 anos $(2,9 \%$ a.a., de 1984 a 2013, segundo dados das Contas Nacionais do IBGE). Outros estudos com modelos EGC que utilizam um cenário de referência de longo prazo adotam números próximos a esse, como Ferreira Filho e Horridge (2014), que assumem um crescimento de 3,5\% a.a.; Magalhães (2013), de 4\% a.a.; e Souza e Domingues (2014), de 3\% a.a. 
É considerado um aumento de 4,25\% e 2,01\% nas exportações de soja e bovinos, respectivamente, o que no acumulado representa aumento total de $130 \%$ das exportações de soja e de $49 \%$ das exportações de bovinos em 2030. As exportações dos demais produtos são endógenas entre 2012 e 2030 e aumentam ao longo do tempo, seguindo a trajetória de crescimento da economia. A Tabela 3 mostra o cenário de crescimento hipotético da economia nacional utilizado.

Tabela 3 Variáveis do cenário macroeconômico para o período de 2012 a 2030 em variação \%

\begin{tabular}{lrrr}
\hline Variável & média anual 2012-2030 & acumulado 2030 \\
\hline PIB agregado & 3,00 & 57,00 \\
\hline Consumo das Famílias & 3,00 & 57,00 \\
\hline Gastos do Governo & 3,00 & 57,00 \\
\hline Crescimento populacional & 1,00 & 19,00 \\
\hline Preço médio dos importados & 3,00 & 57,00 \\
\hline
\end{tabular}

Fonte: Elaboração própria com base no cenário econômico projetado.

\section{Análise e discussão dos resultados}

\subsection{Resultados macroeconômicos regionais}

Dado o cenário de referência apresentado na seção anterior, os resultados regionais para o cenário de crescimento são determinados endogenamente no modelo REGIA (Tabela 4).

A última linha da tabela apresenta os resultados macroeconômicos para a Amazônia Legal em variação percentual no acumulado de 2030. Os resultados para as demais mesorregiões são apresentados como um desvio acumulado em 2030 em relação ao valor apresentado pela Amazônia Legal. $O$ crescimento do PIB regional indica que as regiões de Madeira Guaporé, Leste Rondoniense, Sul do Amapá e Norte Mato-Grossense são as mais beneficiadas nesse cenário de crescimento econômico. O cenário macroeconômico apresenta elevado aumento do consumo e do investimento (acima de 3\% ao ano, em média), e, consequentemente, as regiões com parcela maior desses indicadores no PIB são mais beneficiadas. $\mathrm{Ou}$ seja, o mercado interno apresenta maior relevância, e o comércio externo 
tem crescimento menor. $O$ cenário de crescimento utilizou uma projeção do aumento das exportações de soja e bovinos, o que também favoreceria regiões especializadas nesses dois setores.

Tabela 4 Resultados macroeconômicos mesorregionais do cenário de crescimento para o período de 2006 a 2030 (acumulado em variação \% em relação ao resultado para a Amazônia Legal)

\begin{tabular}{|c|c|c|c|c|c|c|c|c|}
\hline Mesorregiões* & 告 & m $\frac{\bar{\sigma}}{\overline{0}}$ & 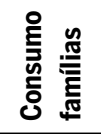 & $\begin{array}{l}\text { 을 } \\
\text { ठํㅇ }\end{array}$ & 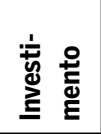 & $\begin{array}{l}\text { 융 } \\
\text { 흘 }\end{array}$ & 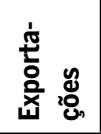 & 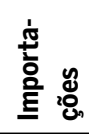 \\
\hline Madeira-Guaporé & RO & $+13,14$ & $+10,55$ & $+8,80$ & $+7,88$ & $+7,68$ & $-3,61$ & $+13,61$ \\
\hline Leste Rondoniense & RO & $+13,18$ & $+17,19$ & $+14,73$ & $+11,28$ & $+12,14$ & $-1,68$ & $+10,64$ \\
\hline Vale do Juruá & $A C$ & $+6,38$ & $+9,05$ & $+7,45$ & $-2,11$ & $+6,65$ & - & $+9,80$ \\
\hline Vale do Acre & $A C$ & $+8,74$ & $+7,71$ & $+6,28$ & $+8,93$ & $+5,78$ & - & $+10,37$ \\
\hline Norte Amazonense & AM & $-11,81$ & $+0,97$ & $+0,23$ & $-11,93$ & $+1,22$ & - & - 7,90 \\
\hline Sudoeste Amazonense & AM & $+0,69$ & $+10,60$ & $+8,80$ & $-0,96$ & $+7,66$ & - & $-0,68$ \\
\hline Centro Amazonense & AM & $-13,87$ & $-28,49$ & $-26,03$ & - 7,17 & $-18,59$ & $+10,07$ & $-13,74$ \\
\hline Sul Amazonense & AM & $+0,48$ & $+11,97$ & $+10,06$ & $-5,51$ & $+8,62$ & $-47,87$ & $-0,40$ \\
\hline Norte de Roraima & RR & $+2,92$ & $-4,77$ & $-4,89$ & $-6,74$ & $-2,61$ & $-8,41$ & $+3,51$ \\
\hline Sul de Roraima & RR & $+6,13$ & $+3,66$ & $+2,65$ & $-11,60$ & $+3,05$ & $-12,39$ & $+8,28$ \\
\hline Baixo Amazonas & PA & $+1,60$ & $+3,95$ & $+2,91$ & $-2,99$ & $+3,24$ & $+2,45$ & $+2,74$ \\
\hline Marajó & PA & $-7,17$ & $+3,90$ & $+2,87$ & $-11,88$ & $+3,21$ & - & $-3,37$ \\
\hline Metropolitana de Belém & PA & $+2,40$ & $-3,44$ & $-3,65$ & $+5,60$ & $-1,71$ & $+7,00$ & $+2,70$ \\
\hline Nordeste Paraense & PA & $-7,76$ & $+2,86$ & $+1,95$ & $-15,90$ & $+2,51$ & $-21,51$ & $-6,19$ \\
\hline Sudoeste Paraense & PA & $+1,74$ & $+10,59$ & $+8,87$ & $-6,35$ & $+7,74$ & $-17,95$ & $+0,90$ \\
\hline Sudeste Paraense & PA & $+2,53$ & $+2,18$ & $+1,38$ & $+5,86$ & $+2,10$ & $+5,95$ & $+4,17$ \\
\hline Norte do Amapá & AP & $+3,78$ & $+2,15$ & $+1,35$ & $+6,12$ & $+2,08$ & - & $+5,86$ \\
\hline Sul do Amapá & AP & $+9,51$ & $+1,09$ & $+0,36$ & $+5,52$ & $+1,36$ & $-6,81$ & $+9,69$ \\
\hline Ocidental do Tocantins & TO & $+0,50$ & $+3,69$ & $+2,70$ & $-1,07$ & $+3,07$ & $-13,48$ & $+0,85$ \\
\hline Oriental do Tocantins & TO & $+4,12$ & $+4,32$ & $+3,28$ & $+14,08$ & $+3,51$ & $-15,63$ & $+6,92$ \\
\hline Norte Maranhense & MA & $+6,15$ & $+2,08$ & $+1,32$ & $+13,69$ & $+2,08$ & $+3,95$ & $+6,71$ \\
\hline Oeste Maranhense & MA & $+1,57$ & $+6,99$ & $+5,64$ & $+2,20$ & $+5,29$ & $+2,40$ & $+3,18$ \\
\hline Centro Maranhense & MA & $+2,15$ & $+12,04$ & $+10,12$ & $-1,32$ & $+8,66$ & $+1,87$ & $+3,81$ \\
\hline Leste Maranhense & MA & $+2,00$ & $+4,83$ & $+3,73$ & $+1,50$ & $+3,88$ & $+0,24$ & $+4,80$ \\
\hline Sul Maranhense & MA & $-0,16$ & $+5,73$ & $+4,49$ & $+1,92$ & $+4,41$ & $+1,63$ & $+4,88$ \\
\hline Norte Mato-Grossense & MT & $+8,16$ & $+17,54$ & $+15,01$ & $+0,29$ & $+12,32$ & $+11,00$ & $+6,81$ \\
\hline Nordeste Mato-Grossense & MT & $+2,30$ & $+13,61$ & $+11,50$ & $-8,96$ & $+9,68$ & $+9,98$ & $+0,90$ \\
\hline
\end{tabular}




\begin{tabular}{|c|c|c|c|c|c|c|c|c|}
\hline Mesorregiões* & 岇 & 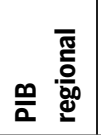 & 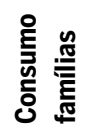 & $\begin{array}{l}\text { 옹 } \\
\text { 엉 }\end{array}$ & 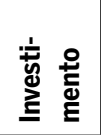 & $\begin{array}{l}\text { 웅 } \\
\text { 흘 }\end{array}$ & 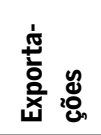 & 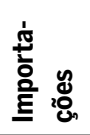 \\
\hline Sudoeste Mato-Grossense & MT & $+6,55$ & $+12,41$ & $+10,50$ & $-5,83$ & $+8,97$ & $+10,41$ & $+4,97$ \\
\hline Centro-Sul Mato-Grossense & MT & $+5,47$ & $+3,60$ & $+2,61$ & $+15,17$ & $+2,99$ & $+10,39$ & $+6,98$ \\
\hline Sudeste Mato-Grossense & MT & $-16,24$ & $-8,51$ & $-8,21$ & $-20,72$ & $-5,15$ & $+12,42$ & $-10,88$ \\
\hline Amazônia Legal ${ }^{* *}$ & . & 125,47 & 145,61 & 119,40 & 106,29 & 63,75 & 58,24 & 109,51 \\
\hline
\end{tabular}

Fonte: Elaboração própria com base nos resultados das simulações com o modelo REGIA.

* Os resultados para as mesorregiões são apresentados como desvio acumulado (variação percentual) em relação ao crescimento apresentado pela Amazônia Legal.

** Os resultados para a Amazônia Legal estão apresentados em variação percentual acumulada (de 2006 a 2030).

As regiões de Madeira Guaporé e Sul do Amapá se destacam por apresentarem elevada participação do consumo no PIB, ao passo que o Leste Rondoniense tem a sua economia estimulada pelo aumento da demanda externa por carne, já que é uma região importante na produção de bovinos. O Norte Mato-Grossense é impulsionado pelo aumento da demanda de soja e bovinos, uma vez que é a maior região produtora na Amazônia. De modo geral, as regiões agrícolas obtiveram resultados acima da Amazônia principalmente por causa das projeções de aumento na demanda externa de soja e bovinos. A região do Centro Amazonense apresenta crescimento do PIB, investimento, gasto do governo, consumo das famílias e emprego, significativamente abaixo da média da Amazônia Legal. O Centro Amazonense, onde se localiza a Zona Franca de Manaus, possui quase $90 \%$ de sua produção nos setores industriais e de serviços. Embora esse esteja crescendo abaixo da Amazônia em alguns indicadores, as suas exportações crescem acima (10\%), o que se explica por ser a maior região exportadora da região.

Analisado o crescimento dos indicadores na Amazônia, apresenta-se o resultado para o emprego em grupo de setores. A Tabela 5 mostra a variação percentual do emprego na agricultura, pecuária, silvicultura e exploração florestal, indústria, serviços e setor público, em relação ao crescimento do emprego na Amazônia Legal. Alguns setores, em determinadas mesorregiões, são mais dinâmicos. Esse é o caso da agricultura no Norte Mato-Grossense, que tem o emprego impulsionado principalmente pelo aumento da produção no setor de soja, graças ao aumento da demanda externa.

O crescimento do emprego na pecuária no Sul do Amapá também ficou acima do da Amazônia.Tal crescimento se explica em razão de uma remu- 
neração mais baixa do trabalho e também porque o setor de bovinos é um importante setor agrícola na mesorregião. O emprego no setor de Silvicultura e Exploração Florestal cresceria mais nas mesorregiões do Sudoeste e do Sul Amazonense e Sudoeste Paraense, 3\% acima do crescimento na Amazônia. Essa é uma atividade importante na estrutura produtiva dessas mesorregiões, representando mais de $13 \%$ da produção da Amazônia. $O$ Leste Rondoniense apresenta o maior crescimento do emprego nos setores de serviços e público. Em conjunto, esses setores representam cerca de $30 \%$ de toda a produção dessa mesorregião.

Em relação à dinâmica do emprego na Indústria, observa-se que o crescimento total na Amazônia está abaixo da maioria de suas mesorregiões. Isso é explicado pelo pequeno crescimento do emprego na mesorregião Centro Amazonense - região onde a indústria tem maior representatividade-, que acaba pressionando a taxa de crescimento da Amazônia para baixo. Ainda, o Centro Amazonense é responsável por cerca de $50 \%$ de toda a remuneração do trabalho da região. Em geral, as mesorregiões da Amazônia são voltadas às atividades agrícolas, sendo significativo apenas o crescimento do emprego industrial na Metropolitana de Belém, no Sudeste Paraense e no Norte Mato-Grossense.

Tabela 5 Crescimento do emprego no cenário de crescimento de 2006-2030 (acumulado em variação \% em relação ao resultado para a Amazônia Legal)

\begin{tabular}{|c|c|c|c|c|c|c|c|}
\hline Mesorregiões* & 岇 & 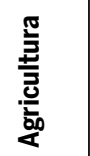 & 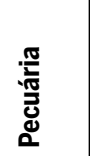 & 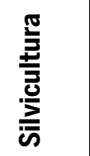 & 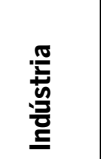 & 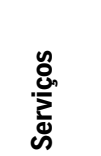 & $\frac{8}{\frac{8}{0}}$ \\
\hline Madeira-Guaporé & RO & $+4,49$ & $+5,08$ & $+1,52$ & $+13,24$ & $+6,82$ & $+6,82$ \\
\hline Leste Rondoniense & RO & $+5,66$ & $+4,80$ & $-0,23$ & $+14,74$ & $+10,56$ & $+10,92$ \\
\hline Vale do Juruá & $A C$ & $+0,55$ & $+1,16$ & $+2,52$ & $+17,48$ & $-0,21$ & $+6,02$ \\
\hline Vale do Acre & $A C$ & $+1,92$ & $+2,13$ & $+0,48$ & $+16,07$ & $+3,86$ & $+5,45$ \\
\hline Norte Amazonense & AM & $-1,24$ & - & $-1,59$ & - & - & $-5,11$ \\
\hline Sudoeste Amazonense & AM & $+2,23$ & $-3,04$ & $+3,37$ & $+4,47$ & $+3,00$ & $+6,04$ \\
\hline Centro Amazonense & AM & $+2,21$ & $-8,08$ & $-2,28$ & $-9,58$ & $-11,92$ & $-17,77$ \\
\hline Sul Amazonense & AM & $+5,66$ & $-2,25$ & $+4,86$ & $+12,36$ & $+1,96$ & $+5,88$ \\
\hline Norte de Roraima & RR & $+3,21$ & $-1,52$ & $+1,61$ & $+9,21$ & $-4,81$ & $-3,67$ \\
\hline Sul de Roraima & $\mathrm{RR}$ & $+0,39$ & $-2,40$ & $+2,24$ & $+11,81$ & $-7,66$ & $-4,50$ \\
\hline Baixo Amazonas & PA & $+2,61$ & $+0,24$ & $+1,43$ & $+9,91$ & $+0,23$ & $+1,61$ \\
\hline
\end{tabular}




\begin{tabular}{|c|c|c|c|c|c|c|c|}
\hline Mesorregiões* & 岇 & 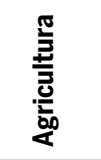 & $\begin{array}{l}\text { 恶 } \\
\text { 戛 } \\
\text { d }\end{array}$ & 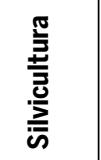 & $\begin{array}{l}\text { 몰 } \\
\text { 氖 } \\
\text { 를 }\end{array}$ & 芯 & $\frac{\text { 음 }}{\text { 음 }}$ \\
\hline Marajó & PA & $+0,87$ & $-1,03$ & $-1,22$ & $+7,48$ & $-1,54$ & $+1,54$ \\
\hline Metropolitana de Belém & PA & $-10,74$ & $-0,40$ & $+0,24$ & $+11,08$ & $+0,26$ & $-1,71$ \\
\hline Nordeste Paraense & PA & $-3,41$ & $-3,32$ & $+1,35$ & $+9,00$ & $-2,11$ & $+1,67$ \\
\hline Sudoeste Paraense & PA & $+3,89$ & $+2,50$ & $+3,22$ & $+8,75$ & $+1,87$ & $+5,42$ \\
\hline Sudeste Paraense & PA & $+4,40$ & $+0,45$ & $+0,82$ & $+10,99$ & $+1,60$ & $+2,15$ \\
\hline Norte do Amapá & AP & $+0,23$ & $+5,82$ & $+2,72$ & $-0,14$ & $-0,75$ & $+1,26$ \\
\hline Sul do Amapá & AP & $-0,03$ & $+7,70$ & $-0,34$ & $+12,79$ & $+1,59$ & $+0,92$ \\
\hline Ocidental do Tocantins & TO & $-4,83$ & $+2,12$ & $-4,93$ & $+15,54$ & $+1,39$ & $+3,15$ \\
\hline Oriental do Tocantins & TO & $-0,86$ & $+1,99$ & $-7,45$ & $+13,49$ & $+2,27$ & $+3,30$ \\
\hline Norte Maranhense & MA & $+1,25$ & $-0,40$ & $-4,16$ & $+14,57$ & $+3,36$ & $+2,35$ \\
\hline Oeste Maranhense & MA & $-1,67$ & $-2,05$ & $-4,09$ & $+12,01$ & $+4,13$ & $+4,54$ \\
\hline Centro Maranhense & MA & $+2,79$ & $-0,32$ & $+0,16$ & $+14,28$ & $+5,25$ & $+6,08$ \\
\hline Leste Maranhense & MA & $-7,50$ & $-1,71$ & $-4,37$ & $+13,06$ & $+4,78$ & $+4,11$ \\
\hline Sul Maranhense & MA & $+0,69$ & $-4,07$ & $-12,69$ & $+11,63$ & $+4,85$ & $+3,49$ \\
\hline Norte Mato-Grossense & MT & $+10,78$ & $+1,44$ & $-1,19$ & $+9,58$ & $+7,38$ & $+9,30$ \\
\hline Nordeste Mato-Grossense & MT & $+4,28$ & $+1,27$ & $-0,80$ & $+9,80$ & $+2,35$ & $+5,56$ \\
\hline Sudoeste Mato-Grossense & MT & $+5,85$ & $+2,45$ & $-1,73$ & $+7,19$ & $+5,61$ & $+7,44$ \\
\hline Centro-Sul Mato-Grossense & MT & $-4,98$ & $+0,05$ & $-8,25$ & $+13,04$ & $+4,10$ & $+3,75$ \\
\hline Sudeste Mato-Grossense & MT & $-14,72$ & $-9,05$ & $-12,03$ & $+9,11$ & $-4,27$ & $-0,51$ \\
\hline Amazônia Legal** & - & 70,65 & 77,61 & 64,98 & 46,96 & 60,65 & 68,66 \\
\hline
\end{tabular}

Fonte: Elaboração própria com base nos resultados das simulações com o modelo REGIA.

* Os resultados para as mesorregiões são apresentados como desvio acumulado (variação percentual) em relação ao crescimento apresentado pela Amazônia Legal.

** Os resultados para a Amazônia Legal estão apresentados em variação percentual acumulada (de 2006 a 2030).

\subsection{Principais resultados setoriais que condicionam as modifica- ções no uso da terra}

Em um modelo EGC, o crescimento dos setores depende do preço do produto setorial e do seu custo de produção, que, por sua vez, é formado pelo preço dos insumos intermediários e pelos fatores de produção (capital, trabalho e terra). Desse modo, a atividade é positivamente afetada 
quando ocorre aumento no preço de seu produto e/ou redução dos custos de produção. O comportamento desses indicadores ajuda na compreensão dos resultados setoriais. $O$ crescimento dos setores de soja, bovinos e exploração florestal e silvicultura podem ser observados pela Figura 2.

Nota-se que a atividade de soja cresceria mais no Norte de Roraima e no Norte Mato-Grossense, $178 \%$ e $163 \%$, respectivamente. Contudo, a produção de soja no Norte de Roraima é pouco representativa $(0,2 \%$ do total produzido na Amazônia), tornando esse resultado pouco significativo. Já o Norte Mato-Grossense representa $60 \%$ de toda a produção de soja da Amazônia. O estímulo do crescimento econômico, aliado ao cenário de crescimento das exportações de soja, faz com que esse setor cresça acima dos demais.

A produção de bovinos é importante na Amazônia, responsável por cerca de $30 \%$ da produção nacional, e um dos principais vetores do desmatamento. A sua produção é concentrada no Leste Rondoniense, no Sudeste Paraense, no Norte e no Sudoeste Mato-Grossense. Observa-se, pela Figura 2, que as regiões com maior crescimento seriam o Sul do Amapá, o Madeira Guaporé e o Sudoeste Paraense. Mas são regiões menos significativas na produção de bovinos e sua maior dinâmica se explica pelo baixo custo de fatores e grande quantidade de terra passível para conversão em pasto. As regiões mais expressivas na produção de bovinos cresceram entre de $1,6 \%$ e $5 \%$ acima do crescimento do setor na Amazônia. O Nordeste Paraense e o Sudeste Mato-Grossense apresentam as mais baixas taxas de crescimento graças aos maiores custos de produção dessas regiões, assim como a dificuldade de expansão da oferta de terra.

O setor exploração florestal e silvicultura apresenta produção significativa no Sudeste e no Nordeste Paraense. A Figura 2 mostra que o Sul Amazonense e o Sudoeste Paraense têm o maior crescimento acumulado na atividade de exploração florestal e silvicultura. Esse setor corresponde a mais de $15 \%$ da produção dessas mesorregiões. Em seguida, apresentam-se Vale Juruá, Sudoeste Amazonense, Norte e Sul de Roraima e Norte do Amapá. Com exceção do Sul de Roraima e do Sudoeste Amazonense, as demais regiões são pouco dependentes desse setor em sua estrutura produtiva (que representa menos de $4 \%$ de sua produção total). Nota-se que as regiões com restrição na expansão da oferta de terra (que não possuem áreas de florestas) crescem menos do que as regiões com maior disponibilidade do fator. 
Figura 2 Crescimento da produção de soja, bovinos e exploração florestal e silvicultura (em variação \%) no cenário de crescimento: acumulado 2006 a 2030

PRODUÇÃO DE SOJA (EM VAR. \%)

CENÁRIO DE REFERÊNCIA - ACUMULADO 2030

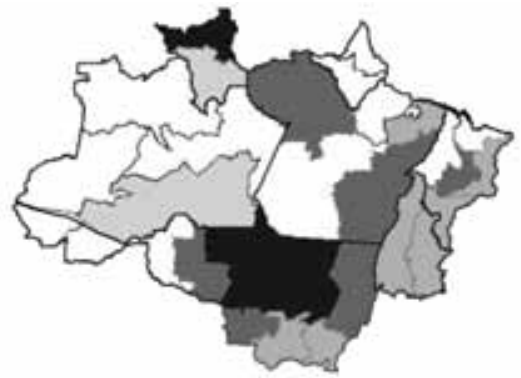

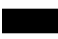

$162.79-178,31$

$141,20-158,37$

$108,92-126,58$

$42,11-46,70$

0,00
PRODUÇÃO DE BOVINOS (EM VAR. \%)

CENÁRIO DE REFERÊNCIA - ACUMULADO 2030
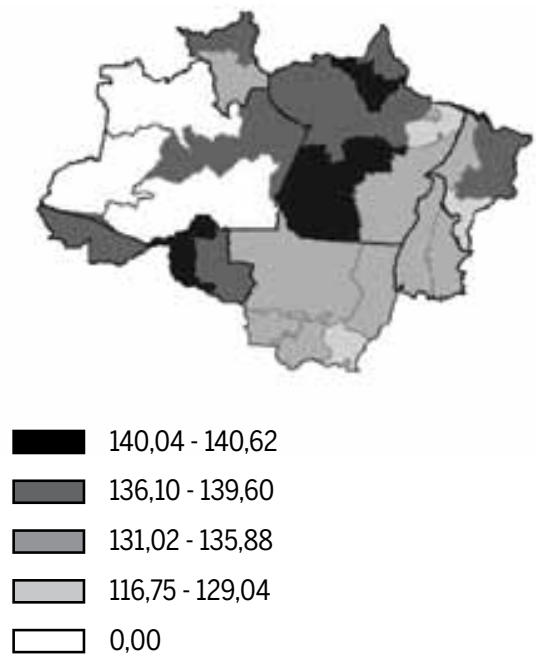

\section{PRODUÇÃO DE SILVICULTURA (EM VAR. \%)}

CENÁRIO DE REFERÊNCIA - ACUMULADO 2030
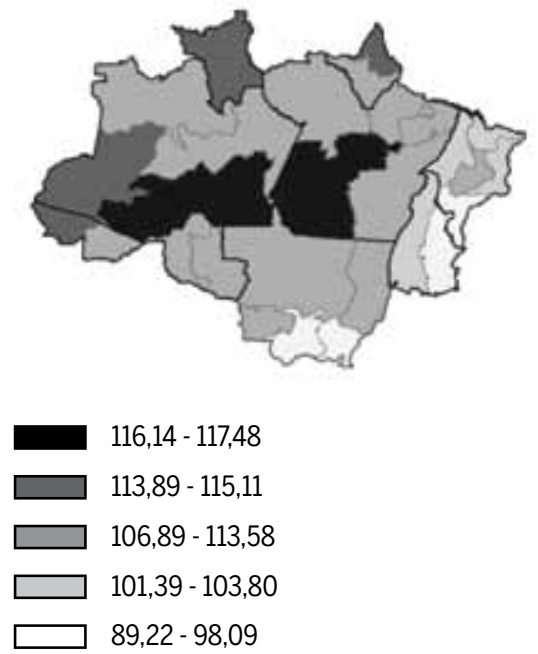

Fonte: Elaboração própria com base nos resultados das simulações com o modelo REGIA. 


\subsection{Resultados de modificação no uso da terra e do desmatamento}

A Figura 3 apresenta a trajetória ao longo do tempo da quantidade de terra agregada na Amazônia Legal (em milhões de hectares) para cada um dos usos do modelo (lavoura, pasto, floresta plantada e floresta natural). No REGIA, para que a área total se mantenha fixa, o crescimento de determinado uso da terra implica redução de um ou mais usos. Desse modo, nota-se que o crescimento das áreas de lavoura, pasto e floresta plantada acontece em razão da redução da área de floresta natural.

Figura 3 Projeção acumulada (2006-2030) do uso da terra (em milhões de hectares) no cenário de crescimento para a Amazônia

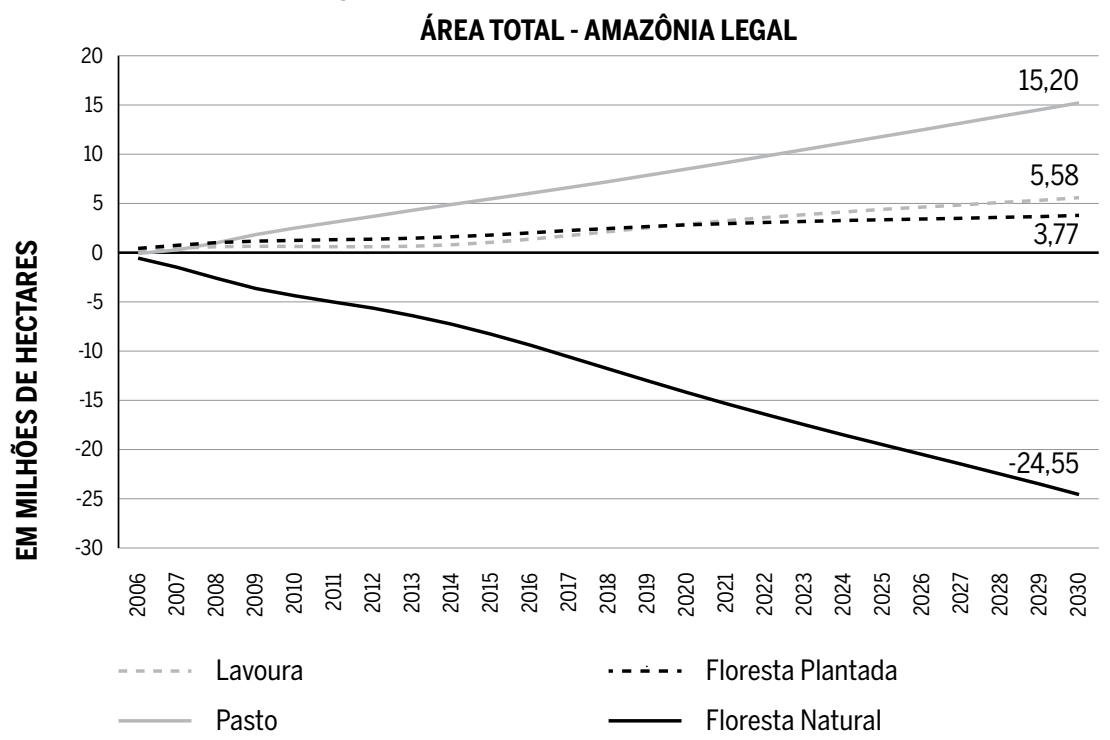

Fonte: Elaboração própria com base nos resultados das simulações com o modelo REGIA.

Observa-se que o modelo projeta, entre 2006 e 2030, aumento de 15 milhões de hectares nas áreas de pasto da Amazônia e que essa apresenta a trajetória mais ascendente entre os diferentes usos da terra. A área total de lavoura aumenta cerca de cinco milhões de hectares, e a área de floresta plantada manteria um crescimento quase constante, elevando sua área total em quase quatro milhões de hectares em 2030. Entre 2006 e 2011, a perda de área de floresta natural (em torno de cinco milhões de hectares) foi constatada pelos dados regionais observados de desmatamento divul- 
gados pelo INPE. ${ }^{24}$ A partir de 2012, essas taxas de desmatamento são endógenas e influenciadas pelo crescimento econômico das mesorregiões. Nota-se que a trajetória descendente se torna mais acentuada a partir de 2016, totalizando uma redução adicional de 19 milhões de hectares de 2012 a 2030, representando o desmatamento médio de 2,1 milhões de hectares na Amazônia no período. Esse valor não é muito elevado se comparado ao desmatamento passado da região, isto é, de aproximadamente 30 milhões de hectares em um período de 15 anos ou de 2 milhões de hectares anuais (de 1990 a 2005). Assim, os mecanismos do modelo parecem capturar adequadamente as tendências econômicas de modificação no uso da terra.

O cenário projetado de crescimento da economia gera aumento na utilização dos fatores de produção. O comportamento da quantidade de terra para cada uso é determinado, principalmente, pela variação da remuneração dos usos. De modo geral, pode-se constatar, pelos resultados do modelo, que a remuneração do pasto está aumentando ao longo do tempo na Amazônia, relativamente à remuneração dos demais usos de terra. Isso leva a um processo de conversão, principalmente, de áreas de floresta natural para áreas de pasto. Conforme explicitado no capítulo de módulo de uso da terra, a matriz de transição representa as possibilidades de conversão entre os usos, e a direção dessa conversão se dá basicamente de floresta natural para pasto e desse para lavoura.

Outro fator que determina esse resultado são as projeções de aumento na demanda externa por bovinos e soja. Nessas projeções, o crescimento das exportações desses produtos contribui para tornar as áreas para pasto e lavoura mais atrativas, estimulando a conversão de floresta para usos agrícolas. No caso das áreas para floresta plantada, nota-se que o aumento é explicado pelo crescimento da economia, que gera maior produção na silvicultura e exploração florestal. Mas as possibilidades de conversão de floresta plantada são mais limitadas que para os demais usos na matriz de conversão. Isso significa que uma conversão maior em direção a esse tipo de uso apenas seria possível com um significativo aumento da sua remuneração relativamente aos demais usos, o que não ocorre.

24 Vale ressaltar que, embora as taxas de desmatamento sejam exógenas entre 2006 e 2011 (valores divulgados pelo programa PRODES-INPE), a realocação dessa área entre as áreas de pasto e lavoura é determinada endogenamente dentro do módulo de mudança indireta do uso da terra (ILUC) no modelo REGIA. 
No caso de floresta natural, observa-se uma trajetória descendente ao longo do tempo, que possibilita o aumento das áreas dos sistemas agroflorestais na Amazônia. Esse fato pode ser interpretado como um aumento da remuneração dos demais usos relativamente à remuneração de floresta natural, o que leva a uma conversão dessa para os usos agrícolas. Portanto, a conversão de áreas de floresta natural para os demais usos vai depender da remuneração de cada uso da terra, assim como das possibilidades de conversão dadas pela matriz de transição e da elasticidade da oferta de terra regional. Isso indica que, quanto maior a área que pode potencialmente ser convertida, mais fácil a conversão.

A Tabela 6 mostra o que acontece em cada mesorregião da Amazônia com as áreas de lavoura, pasto, floresta plantada e floresta natural, em milhões de hectares e variação percentual no cenário de crescimento (variação acumulada entre 2006 e 2030). Analisando, primeiramente, as áreas de lavoura, nota-se pela Tabela 6 que a região que mais amplia essa área é o Norte Mato-Grossense, com 2,11 milhões de hectares a mais em 2030. O crescimento do setor de soja, que representa aproximadamente $14 \%$ de tudo o que é produzido no Norte Mato-Grossense, contribui para esse resultado, com o aumento da remuneração de terra para a lavoura, tornando atrativa a conversão de outros usos de terra para esse uso. As demais regiões citadas apresentam uma conversão em direção ao uso da lavoura, principalmente por causa do crescimento dos setores de mandioca e de outros produtos da lavoura. Norte de Roraima, Sul de Roraima, Sul Amazonense, Madeira Guaporé e Sudoeste Paraense obtiveram a maior taxa de crescimento das áreas de lavoura, entre $65 \%$ e $78 \%$. Tal resultado é explicado pelo aumento da remuneração da lavoura em relação aos demais usos, pelas elasticidades maiores da oferta da terra em cada mesorregião e pelas possibilidades de conversão dada pela matriz de transição.

As áreas de pasto, em milhões de hectares, aumentam mais que as áreas de lavoura. Isso sugere que a remuneração do pasto também aumenta no cenário de crescimento. Além disso, a matriz de transição ilustra o fato de que é mais fácil a conversão de terra de florestas naturais para as áreas de pasto do que para os demais usos. As mesorregiões Sudeste Paraense, Norte Mato-Grossense e Sudoeste Paraense apresentam a maior expansão da área para pasto. De acordo com a base de dados do REGIA, essas regiões possuem mais de $13 \%$ de sua produção total no setor de pecuária. Além disso, a pecuária é impulsionada também pelo crescimento das exportações de bovinos. 
Tabela 6 Variação das áreas de lavoura, pasto, floresta plantada e floresta natural (em milhões de hectares) no cenário de crescimento - acumulado 2006 a 2030

\begin{tabular}{|c|c|c|c|c|c|c|c|c|c|}
\hline \multirow[b]{2}{*}{ Mesorregiões* } & \multirow[b]{2}{*}{ 岇 } & \multicolumn{4}{|c|}{ Em milhões de hectares } & \multicolumn{4}{|c|}{ Em variação \% } \\
\hline & & 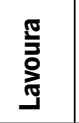 & 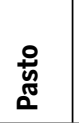 & 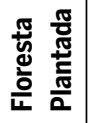 & 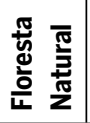 & 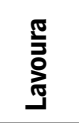 & 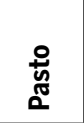 & 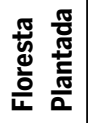 & 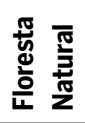 \\
\hline Madeira-Guaporé & RO & 0,07 & 1,17 & 0,08 & $-1,31$ & 65,69 & 69,43 & 62,04 & $-15,08$ \\
\hline Leste Rondoniense & RO & 0,09 & 1,13 & 0,05 & $-1,26$ & 25,67 & 24,59 & 16,46 & $-18,42$ \\
\hline Vale do Juruá & AC & 0,15 & 0,10 & 0,04 & $-0,29$ & 52,42 & 58,58 & 46,41 & $-4,06$ \\
\hline Vale do Acre & $A C$ & 0,26 & 0,47 & 0,02 & $-0,75$ & 38,67 & 42,26 & 33,36 & $-12,56$ \\
\hline Norte Amazonense & AM & 0,03 & 0,00 & 0,02 & $-0,06$ & 50,55 & 44,24 & 45,67 & $-0,14$ \\
\hline Sudoeste Amazonense & AM & 0,14 & 0,03 & 0,03 & $-0,21$ & 54,78 & 62,71 & 46,57 & $-0,58$ \\
\hline Centro Amazonense & AM & 0,28 & 0,18 & 0,15 & $-0,62$ & 56,28 & 54,45 & 45,12 & $-1,84$ \\
\hline Sul Amazonense & AM & 0,09 & 0,45 & 0,09 & $-0,64$ & 73,70 & 70,31 & 65,30 & $-1,37$ \\
\hline Norte de Roraima & $\mathrm{RR}$ & 0,05 & 0,09 & 0,02 & $-0,17$ & 74,56 & 68,46 & 60,12 & $-1,87$ \\
\hline Sul de Roraima & RR & 0,04 & 0,22 & 0,05 & $-0,31$ & 75,62 & 80,26 & 73,92 & $-2,71$ \\
\hline Baixo Amazonas & PA & 0,49 & 0,44 & 0,30 & $-1,24$ & 51,03 & 62,09 & 40,61 & $-4,23$ \\
\hline Marajó & PA & 0,23 & 0,04 & 0,07 & $-0,33$ & 59,15 & 50,45 & 33,42 & $-3,06$ \\
\hline Metropolitana de Belém & PA & $-0,04$ & 0,01 & 0,05 & $-0,02$ & $-7,07$ & 19,62 & 80,75 & $-16,16$ \\
\hline Nordeste Paraense & PA & 0,21 & 0,00 & 0,60 & $-0,81$ & 18,26 & 16,57 & 55,54 & $-26,85$ \\
\hline Sudoeste Paraense & PA & 0,16 & 1,77 & 0,55 & $-2,47$ & 78,47 & 79,91 & 57,09 & $-6,23$ \\
\hline Sudeste Paraense & PA & 0,09 & 3,17 & 1,34 & $-4,60$ & 30,34 & 34,06 & 29,38 & $-25,69$ \\
\hline Norte do Amapá & AP & 0,03 & 0,01 & 0,01 & $-0,05$ & 57,39 & 80,35 & 58,21 & $-1,01$ \\
\hline Sul do Amapá & AP & 0,06 & 0,04 & 0,01 & $-0,11$ & 49,32 & 65,62 & 47,94 & $-1,39$ \\
\hline Ocidental do Tocantins & TO & 0,05 & $-0,17$ & $-0,03$ & 0,15 & 2,26 & 0,48 & $-2,52$ & $-0,54$ \\
\hline Oriental do Tocantins & TO & 0,00 & $-0,10$ & 0,00 & 0,11 & $-2,89$ & 0,31 & 3,60 & $-0,01$ \\
\hline Norte Maranhense & MA & 0,39 & 0,14 & 0,00 & $-0,53$ & 46,66 & 28,05 & 5,65 & $-16,64$ \\
\hline Oeste Maranhense & MA & 0,04 & 0,89 & 0,01 & $-0,93$ & 19,64 & 26,91 & 10,65 & $-19,55$ \\
\hline Centro Maranhense & MA & 0,08 & 0,69 & 0,07 & $-0,84$ & 51,52 & 54,99 & 37,19 & $-19,55$ \\
\hline Leste Maranhense & MA & 0,01 & 0,01 & 0,00 & $-0,01$ & 6,62 & 7,74 & 18,49 & $-0,86$ \\
\hline Sul Maranhense & MA & 0,03 & $-0,01$ & 0,00 & $-0,02$ & 1,00 & $-2,47$ & $-13,84$ & $-0,05$ \\
\hline Norte Mato-Grossense & MT & 2,11 & 2,88 & 0,18 & $-5,17$ & 54,81 & 41,62 & 30,39 & $-14,62$ \\
\hline Nordeste Mato-Grossense & MT & 0,38 & 1,04 & 0,05 & $-1,48$ & 45,81 & 41,14 & 31,44 & $-11,06$ \\
\hline Sudoeste Mato-Grossense & MT & 0,09 & 0,49 & 0,00 & $-0,58$ & 26,28 & 23,04 & 17,07 & $-14,15$ \\
\hline Centro-Sul Mato-Grossense & MT & 0,00 & 0,02 & 0,00 & $-0,01$ & $-4,08$ & 5,31 & $-8,34$ & $-0,21$ \\
\hline Sudeste Mato-Grossense & MT & $-0,01$ & 0,01 & $-0,01$ & 0,01 & $-0,74$ & 4,25 & $-2,39$ & $-0,03$ \\
\hline
\end{tabular}

Fonte: Elaboração própria com base nos resultados das simulações com o modelo REGIA. 
Em relação à variação percentual da área de pasto, tem-se que Madeira Guaporé, Sul Amazonense, Norte de Roraima, Sul de Roraima, Sudoeste Paraense e Norte do Amapá obtiveram as maiores taxas de crescimento, entre 69\% e $81 \%$. Com exceção da região Sul Amazonense, em que o setor tem pouca representatividade, isto é, menos de $4 \%$ de sua produção total, as demais regiões têm mais de $10 \%$ do seu PIB na pecuária. Além disso, no Sudoeste Paraense, a pecuária representa mais de $20 \%$ de toda a produção. Em termos de área para floresta plantada, observa-se um crescimento menor do que para os demais usos. Esse resultado indica que o crescimento da remuneração desse tipo de uso foi relativamente menor do que o dos demais (com exceção do Sudeste Paraense, que apresenta aumento da área de floresta plantada de aproximadamente 1,4 milhão de hectare). O Sudeste Paraense é o maior produtor de exploração florestal da Amazônia Legal, e produz cerca de $25 \%$ de toda a produção. Em variação percentual, destacam-se o Sul Amazonense e o Sul de Roraima com o maior crescimento, situando-se entre $65 \%$ e $81 \%$. Essas regiões contribuem com aproximadamente $2 \%$ da produção de exploração florestal na Amazônia, sugerindo que esse crescimento não seria significativo para o aumento da produção total.

Nota-se que o Norte Mato-Grossense e o Sudeste Paraense são as regiões que mais perderam área de floresta, 5,2 e 4,6 milhões de hectares, respectivamente. No Sudeste Paraense, $98 \%$ dessa redução se deve ao aumento das áreas de pasto (69\%) e área de floresta plantada (29\%). Isso se explica pela sua dinâmica econômica voltada à produção de bovinos e também com destaque na exploração florestal. Já no Norte Mato-Grossense, da redução de cerca de cinco milhões de hectares de floresta natural, 55\% ocorre em direção às áreas de pasto, e 41\%, à lavoura, já que essa é uma região que se destaca na produção de soja e bovinos. As mesorregiões que apresentam as menores taxas de desmatamento se encontram no Norte Amazonense, no Sudoeste Amazonense e no Norte de Roraima. Essas regiões possuem baixa representatividade na atividade agropecuária da Amazônia, e, portanto, a conversão de floresta natural para uso produtivo é pouco estimulada em razão dos baixos retornos.

\section{Conclusões}

Este artigo apresentou uma metodologia consistente de projeção do desmatamento nas regiões da Amazônia Legal, decorrente de um cenário de 
crescimento da economia brasileira. Para isso, foi empregado um modelo de Equilíbrio Geral Computável (EGC) dinâmico inter-regional, que incorpora um modelo de uso da terra conhecido como ILUC (indirect land use change). A base de dados foi construída por meio de um procedimento computacional de regionalização valendo-se do método desenvolvido por Horridge (2006). A base de dados e o modelo utilizado são inéditos na literatura para as regiões da Amazônia Legal brasileira. Assim, a maior contribuição deste estudo está relacionada à construção de um modelo EGC inédito na literatura, que permite uma análise regional detalhada da Amazônia, acoplado a um módulo de uso da terra, que pode servir como ferramenta para analisar, futuramente, o impacto de políticas públicas como de controle de desmatamento e do novo Código Florestal brasileiro.

O cenário de crescimento econômico regional simulado permitiu analisar detalhadamente os condicionantes e as determinantes das mudanças de uso do solo e do desmatamento. Nesse cenário, os resultados apontaram que as regiões que apresentariam maior crescimento do PIB seriam aquelas que estão no arco do desmatamento (no Mato Grosso, no Pará e na Rondônia), principalmente as regiões produtoras de soja e bovinos. Essas regiões seriam estimuladas nesse cenário pelo crescimento não somente da economia nacional, mas também pelo aumento da demanda por exportações de soja e bovinos. O modelo pode ser alimentado por cenários alternativos de crescimento e de choques (como de investimentos de mineração, de mercados internacionais de commodities agrícolas e restrições de uso do solo), o que sinaliza sua aplicação para uma série de estudos.

O crescimento projetado da economia brasileira, aliado ao aumento da produção desses dois setores, sugere uma dinâmica interessante no que concerne às mudanças no uso da terra na Amazônia. O desmatamento total na região em 19 anos, período de 2012 a 2030, seria comparativamente menor do que aquele ocorrido nos 15 anos anteriores (19 milhões contra 24 milhões de hectares), indicando que o crescimento da economia não aumentaria substancialmente o desmatamento na região. Esse resultado pode ser explicado pela baixa produtividade das atividades agrícolas na região.

Dentro das limitações, as projeções indicaram que a soja apresentaria um crescimento mais acentuado em regiões do Mato Grosso, maior produtor de soja da Amazônia, e que o setor de bovinos destacar-se-ia em regiões localizadas fora do arco do desmatamento, como no Sudoeste Paraense, no Baixo Amazonas, no Centro Amazonense, no Madeira-Guaporé e no Acre. 
A metodologia apresentada neste artigo foca em condicionantes econômicos do uso da terra, como fator produtivo, e não captura o desmatamento ilegal graças à especulação fundiária, à construção de estradas e à extração ilegal de madeira. Portanto, os resultados para o desmatamento nesse cenário podem estar subestimados. Não se trata de uma limitação do modelo, visto que a análise desses fatores deve ser feita por modelos e técnicas específicas a esses assuntos.

Outra característica importante da metodologia utilizada neste estudo é que a questão de vizinhança entre regiões não tem nenhum papel na expansão de cultivos agrícolas ou da pecuária. Com tal limitação, o modelo só permite a expansão de culturas em regiões onde essa cultura já exista, e em grande parte apenas os condicionantes econômicos da própria região influenciam a sua expansão. Ou seja, o modelo não trabalha propriamente com a questão de vizinhança ou expansão da fronteira agrícola, mas com a de expansão local de atividades influenciadas por mecanismos de mercado competitivo, preços relativos e retornos constantes de escala, hipóteses do modelo EGC.

\section{Referências}

ALENCAR, A. et al. Desmatamento na Amazônia: indo além da emergência crônica. Manaus, Instituto de Pesquisa Ambiental da Amazônia (Ipam), p.89, 2004.

ALSTON, L. J. et al. Land reform policies, the sources of violent conflict, and implications for deforestation in the Brazilian Amazon. Journal of Environmental Economics and Management, vol. 39, p. 162-188, 2000.

ANDERSEN, L. E.; REIS, E. J. Deforestation, development, and government Policyin the Brazilian Amazon: An econometric analysis. Texto para Discussão n. 513. Instituto de Pesquisa Econômica Aplicada (IPEA), Rio de Janeiro, 1997.

ARAUJO, C.et al. Land tenure insecurity and deforestation in the Brazilian Amazonia. Correspondance, 2006.

ARAUJO, C. et al. Property rights and deforestation in the Brazilian Amazon. Ecological Economics, vol. 68, p. 2461-2468, 2009.

ARIMA, E. Y. et al. Statistical confirmation of indirect land use change in the Brazilian Amazon. Environmental Research Letters, vol. 6, p. 1-7, 2011.

ARIMA, E.; VERÍSSIMO, A. Brasil em ação: Ameaças e oportunidades econômicas na fronteira amazônica. Série Amazônia no 19. Belém: Imazon, 2002.

ASSUNÇÃO, J. et al. Deforestations lowdown in the Legal Amazon: Pricesor policies? Climate policy initiative. Working Paper, 2012. Disponível em: <http://climatepolicyinitiative. 
org/publication/deforestation-slowdown-in-the-legal-amazon-prices-or-policie/>. Acesso em: 2 out. 2012.

BARONA, E. et al. The role of pasture and soy bean in deforestation of the Brazilian Amazon. Environ. Res. Lett., vol. 5, 2010.

BECKER, B. Os eixos de integração e desenvolvimento e a Amazônia. Revista Território, ano IV, n. 6, p. 29-42, 1999.

BITTENCOURT, F. R. Modelagem dinâmica de distribuição de metas de redução de desmatamento, estimativas de potencial de emissão de gases de efeito estufa e de receitas financeiras via REDD+ em niveis subnacionais. 2011. 230 f. Tese (Doutorado em Saneamento, Meio Ambiente e Recursos Hídricos) - Escola de Engenharia da Universidade Federal de Minas Gerais, Belo Horizonte, 2011.

CARVALHO, T. S. Uso do solo e desmatamento nas regiões da Amazônia Legal brasileira: Condicionantes econômicos e impactos de políticas públicas. 2014. 226 f. (Tese de Doutorado) - Centro de Desenvolvimento e Planejamento Regional da Universidade Federal de Minas Gerais, Belo Horizonte, 2014.

CATTANEO, A. Deforestation in the Brazilian Amazon: Comparing the impacts of macroeconomics shocks, landtenure, and technological change. Land Economics, vol. 77, n.2, p. 219-140, 2001.

CATTANEO, A. Balancing agricultural development and deforestation in the Brazilian Amazon. Research Report 129, International Food Policy Research Institute, Washington D. C., 2002.

CATTANEO, A. Regional comparative advantage, location of agriculture, and deforestation in Brazil. Journal of Sustainable Forestry, vol. 27, p. 25-41, 2008.

CHOMITZ, K. M.; THOMAS, T. S. Determinants of land use in Amazônia: A fine scalespatial analysis. American Journal of Agricultural Economics, vol. 85, p. 1016-1028, 2003.

COSTA, F. A. Corporação e economia local: Uma análise usando Contas Sociais Alfa (CS $\alpha$ ) do programa de investimentos da CVRD no Sudeste Paraense (2004 a 2010). Nova Economia, v. 18, n. 3, p. 429-470, 2008.

DeFRIES, R. S.; ROSENZWEIG, C. Toward a whole-landscape approach for sustainable land use in the tropics. PNAS, vol. 107, n. 46, p. 19627-19632, 2010.

DINIZ, M. B.; OLIVEIRA JUNIOR, J. N.; TROMPIERI NETO, N. T.; DINIZ, N. J. T. Causas do desmatamento da Amazônia: Uma aplicação do teste de causalidade de Granger acerca das principais fontes de desmatamento nos municípios da Amazônia Legal brasileira. Nova Economia, v. 19, n. 1, p. 121-151, 2009.

DINIZ, T. B. Impactos socioeconômicos do Código Florestal Brasileiro: Uma discussão à luz de um modelo de equilíbrio geral computável. 2012. 113 f. (Dissertação de Mestrado) - Escola Superior de Agricultura "Luiz de Queiroz", Universidade de São Paulo, São Paulo, 2012.

DIXON, P. B. et al. ORANI: A multisectoral model of the Australian economy. Amsterdam: North-Holland, 1982. $372 \mathrm{p}$.

FACHINELLO, A. L. Avaliação do impacto econômico de possíveis surtos da gripe aviária no Brasil: Uma análise de equilíbrio geral computável. 2008. 161 f. (Tese de Doutorado) - Escola Superior de Agricultura "Luiz de Queiroz", Universidade de São Paulo, São Paulo, 2008. 
FARIAS, W. R. Modelagem e avaliação de fenômenos relacionados ao uso da terra no Brasil. 2012. 275 f. (Tese de Doutorado) - Universidade de São Paulo, São Paulo, 2012.

FEARNSIDE, F. M. Land-tenure issues as factors in environmental destructionin Brazilian Amazonian: The Case of Southern Pará. World Development, vol. 29, n. 8, p. 1361-1372, 2001.

FERREIRA FILHO, J. B.; HORRIDGE, J. M. The Doha Round, poverty and regional inequality in Brazil. In: HERTEL, T. W. (Eds.). Puttingd evelopment back in to the Doha Agenda: Poverty impacts of a WTO agreement. Washington DC: The International Bank of Reconstructionand Development, Palgrave, McMillan, 2006.

FERREIRA FILHO, J. B.; HORRIDGE, J. M. Would world agricultural trade liberalization help the poor of Brazil? In: $11^{\text {th }}$ Annual Conferenceon Global Economic Analysis, Helsinki, Finland, 2008.

FERREIRA FILHO, J. B.; HORRIDGE, J. M. Climate change impacts on agricultural andi nternal migrations in Brazil. In: $13^{\text {th }}$ Annual Conferenceon Global Economic Analysis, Penang, Malaysia, 2010.

FERREIRA FILHO, J. B.; HORRIDGE, J. M. Climate change impacts on agriculture and internal migrations in Brazil. In: 14 ${ }^{\text {th }}$ Annual Conferenceon Global Economic Analysis, 2011, Venice Proceedings of the $14^{\text {th }}$ Annual Conferenceon Global Economic Analysis, 2011.

FERREIRA FILHO, J. B.; HORRIDGE, J. M. Endogenous land use and supply security in Brazil. General Paper n ${ }^{0}$ G-229. Centre of Policy Studies, CoPS, Monash, 2012.

FERREIRA FILHO, J. B.; HORRIDGE, J. M. Ethanol expansion and indirect land use change in Brazil. Land Use Policy, vol. 36, p. 595-604, 2014.

FERREIRA FILHO, J. B. et al. Tax reform, income distribution and poverty in Brazil: A general equilibrium analysis. MPIA Working Paper 2007-26, Poverty and Economic Policy Research Network - PEP-NET, Québec, 2007.

FERREIRA, A. M. M.; SALATI, E. Forças de transformação do ecossistema amazônico. Estudos Avançados, v. 19, n. 54, 2005.

FOOD AND AGRICULTURE ORGANIZATION OF THE UNITED NATIONS (FAO). World Agriculture: Towards 2015/2030. UK: Earthscan Publications Ltda, 2003. 444 p.

GEIST, H. J.; LAMBIN, E. F. Proximate causes and underlying driving forces of tropical deforestation. BioScience, vol. 52, n. 2, p. 143-150, 2002.

GOUVEllo, C. (Ed.). Estudo de Baixo Carbono para o Brasil. 2010. Disponível em: <http:// siteresources.worldbank.org/BRAZILINPOREXTN/Resources/38171661276778791019/ Relatorio_Principal_integra_Portugues.pdf $>$ Acesso em: 5 set. 2012.

HORRIDGE, M. ORANI-G: Ageneral equilibrium model of the Australian economy. Working Paper OP-93. Cops/Impact: Centre of Policy Studies, Monash University, 2000. Disponível em:<www.monash.edu.au/policy/elecpapr/op93.htm>. Acesso em: 4 fev. 2011.

HORRIGDE, M. Preparing a TERM bottom-up regional database. Preliminary Draft. Centre of Policy Studies, Monash University, 2006.

HORRIDGE, J. M. et al. The impact of the 2002-2003 droughton Australia. Journal of Policy Modeling, vol. 27, n. 3, p. 285-308, 2005.

HORRIDGE, J. M.; WITTWER, G. The economic impacts of a construction project, using 
Sino TERM, a multi-regional CGE model of China. China Economic Review, vol.19, n.4, p. 628-634, 2008.

HORRIDGE, J. M.; WITTWER, G. A multi-regionalr epresentation of China's agricultural sectors. China Agricultural Economic Review, vol. 1, n. 4, p. 420-434, 2009.

INSTITUTO BRASILEIRO DE GEOGRAFIA E ESTATÍSTICA (IBGE). Censo Agropecuário 2006. Rio de Janeiro: IBGE, 2006.

INSTITUTO BRASILEIRO DE GEOGRAFIA E ESTATÍSTICA (IBGE). Sistema IBGE de Recuperação Automática (SIDRA). 2010. Disponível em: <http://www.sidra.ibge.gov.br/>. Acesso em: 20 jan. 2013.

INSTITUTO NACIONAL DE PESQUISAS ESPACIAIS (INPE); COORDENADORIA GERAL DE OBSERVAÇÃO DA TERRA; PROGRAMA AMAZÔNIA - PROJETO PRODES. Metodologia para o Cálculo da Taxa Anual de Desmatamento na Amazônia Legal, outubro de 2013.

INSTITUTO DE PESQUISA ECONÔMICA APLICADA (IPEA). Código florestal: Implicações do PL 1876/99 nas áreas de reserva legal. Comunicados do IPEA, n. 96. 2011.

KRUGMAN, P. Scale economics, product differentiation, and the pattern of trade. American Economic Review, vol. 70, 1980.

MACEDO, D. C. et al. Croplandexpansion changes de forestation dynamics in the Southern Brazilian Amazon. PNAS, vol. 103, n. 39, p. 14637-14641, 2012.

MAGALHÃES, A. S. Economia de baixo carbono no Brasil: Alternativas de políticas e custos de redução de emissões de gases de efeito estufa. 2013. 290 f. (Tese de Doutorado) - Centro de Desenvolvimento e Planejamento Regional daUniversidade Federal de Minas Gerais, Belo Horizonte, 2013.

MARGULIS, S. Causas do desmatamento da Amazônia brasileira. Brasília: Banco Mundial, 2003. $100 \mathrm{p}$.

MERTENS, B. et al. Crossing spatial analyses and lives tock economics to understand deforestation process in Brazilian Amazon: The case of São Felix do Xingu in South Pará. Agricultural Economics, n. 27, p. 269-294, 2002.

MILLER, R.; BLAIR, P. Input-Output analysis: Foundations and extensions. New Jersey: Prentice-Hall, 2009. 782p.

MINISTÉRIO DO MEIO AMBIENTE (MMA). Plano de Prevenção e Controle do Desmatamento na Amazônia. 2012. Disponível em: <http://www.mma.gov.br/florestas/controle-e-preven \%C3\%A7\%C3\%A3o-dodesmatamento/plano-de-a\%C3\%A7\%C3\%A3o-para-amaz\%C3\%B4nia-ppcdam> Acesso em: 5 set. 2012.

MINISTÉRIO DO PLANEJAMENTO, ORÇAMENTO E GESTÃO. Impactos econômicos da carteira de investimentos. In: Estudo da Dimensão Territorial para o Planejamento, Volume VI. MPOG, Secretaria de Planejamento e Investimentos Estratégicos, Brasília, 2008.

NASSAR, A. M. Inserção internacional do agro - caminho sem volta. O Estado de S.Paulo, São Paulo, 16 mar. 2011. Caderno Opinião. Disponível em: <http://opiniao.estadao.com.br/ noticias/geral,insercao-internacional-do-agro-caminho-sem-volta-imp-,692602>

NEPSTAD, D. et al. The end of deforestation in the Brazilian Amazon. Science, vol. 326, p. 1350-1351, 2009. 
PAMBUDI, D.; SMYTH R. Making Indonesia more attractive to foreign investors: A computable general equilibrium analysis of reducing the risk premium in Central Java. Review of Urbanand Regional Development Studies, vol. 20, n.3, 2008.

PATTANAYAK, S. K. et al. Climate change andc onservation in Brazil: CGE evaluation of health and wealth impacts. Economic Geography and Color Maps, vol. 9, n.2, 2009.

PAVÃO, A. R. Impactos econômicos da introdução do milho Bt11 no Brasil: Uma abordagem de equilíbrio geral inter-regional. 2008. 111 f. (Dissertação de Mestrado) - Escola Superior de Agricultura "Luiz de Queiroz", Universidade de São Paulo, São Paulo, 2008.

PFAFF, A. et al. Road investments, spatial spillovers, and deforestation in the Brazilian Amazon. Journal of Regional Science, vol. 47, n. 1, p. 109-123, 2007.

RUDEL, T. K. et al. Agricultural intensification and changes in cultivated areas, 1970-2005. PNAS, vol. 106, n. 49, p. 20675-20680, 2009.

SANTOS, C. V. Politica tributária, nível de atividade econômica e bem-estar: Lições de um modelo de equilíbrio geral inter-regional. 2006. 140 f. (Tese de Doutorado) - Escola Superior de Agricultura "Luiz de Queiroz", Universidade de São Paulo, São Paulo, 2006.

SAWYER, D. R. Possibilidades e limites de formas alternativas de exploração econômica da Amazônia Brasileira. Nova Economia, v. 1, n.1, p. 91-108, 1990.

SOARES-FILHO, B. S. et al. Redução das Emissões de Carbono do Desmatamento no Brasil: O papel do programa Áreas Protegidas da Amazônia (ARPA), WWF, 2009. 8 p.

SOARES FILHO, B. S. et al. Cenário de desmatamento para a Amazônia. Estudos Avançados, v. 19, n. 54, p. 137-152, 2005.

SOUZA, K. B.; DOMINGUES, E. P. Mapeamento e projeção da demanda por engenheiros por categoria, setor e microrregiões brasileiras. Pesquisa e Planejamento Econômico PPE, v. 44, n. 2, 2014.

VAN MEIJL, H. et al. The impact of different policy environments on agricultural land use in Europe. Agriculture, Ecosystems \& Environment, vol. 114, p. 21-38, 2006.

WITTWER, G. Economic modeling of water. London: Springer, 2012.186 p.

\section{Sobre os autores}

Terciane Sabadini Carvalho-tersabadini@gmail.com

Professora na Universidade Federal do Paraná, Curitiba, PR.

Edson Paulo Domingues - domingues.edson@gmail.com

Professor no Cedeplar - Centro de Desenvolvimento e Planejamento Regional / Universidade Federal de Minas Gerais, Belo Horizonte, MG. Bolsista de produtividade em pesquisa do CNPq e bolsista do Programa Pesquisador Mineiro da Fapemig.

\section{Sobre 0 artigo}

Recebido em 23 de outubro de 2014. Aprovado em 27 de fevereiro de 2015. 